\title{
Analysis to energy consumption characteristics and influencing factors of terminal building based on airport operating data
}

Article

Accepted Version

Creative Commons: Attribution-Noncommercial-No Derivative Works 4.0

Gu, X., Xie, J., Luo, Z. ORCID: https://orcid.org/0000-00022082-3958 and Liu, J. (2021) Analysis to energy consumption characteristics and influencing factors of terminal building based on airport operating data. Sustainable Energy

Technologies and Assessments, 44. 101034. ISSN 2213-1388 doi: https://doi.org/10.1016/j.seta.2021.101034 Available at https://centaur.reading.ac.uk/96014/

It is advisable to refer to the publisher's version if you intend to cite from the work. See Guidance on citing.

To link to this article DOI: http://dx.doi.org/10.1016/j.seta.2021.101034

Publisher: Elsevier

All outputs in CentAUR are protected by Intellectual Property Rights law, including copyright law. Copyright and IPR is retained by the creators or other copyright holders. Terms and conditions for use of this material are defined in the End User Agreement. 


\section{www.reading.ac.uk/centaur}

\section{CentAUR}

Central Archive at the University of Reading

Reading's research outputs online 


\section{Analysis to energy consumption characteristics and influencing factors of terminal} building based on Airport operating data

(1)

$$
\text { GU Xianliang }{ }^{1,2}, *, \text { XIE Jingchao }{ }^{1}, \text { LUO Zhiwen }^{3} \text { and LIU Jiaping }{ }^{1, *}
$$

${ }^{1}$ Key Laboratory of Green Built Environment and Energy Efficient Technology, Beijing, Beijing University of Technology, Beijing 100124, China

${ }^{2}$ Beijing Institute of Architectural Design, Beijing 100040, China

${ }^{3}$ School of the Built Environment, University of Reading, UK

\section{Abstract}

Airport terminals have much higher average energy consumptions than normal public buildings. This is caused by their complicated space features and operation characteristics. In China, large modern airports were built from around 2004, which means our understanding to the real energy performance of these buildings lag behind the design practice and with feedback from operation experience, both design or operation of modern airports shall be improved in terms of energy efficiency. Nanning Airport provided an excellent example for that purpose, with comprehensive operation data collected during 2016-2019. The data were firstly presented in this paper, followed by clustering and correlation analysis to establish the correlation among potential factors. From the analysis, the major factors influencing energy consumption were identified as passenger flow, meteorological parameters and supply fan frequency. Regression analysis was performed based on monthly data and equations were provided for the calculation of the terminal total energy consumption and its three sub components according to the input parameters of passenger flow data and meteorological data. These equations provide guidance on energy supply for the operation of this airport and more importantly can be used as valuable reference when designing airports in similar conditions.

Keywords: Airport terminal; Operation data; Energy consumption; influencing factors; Passenger

*Corresponding Authors: GU Xianliang (E-mail: guxl-b2018@foxmail.com); LIU Jiaping (E-mail: liujiaping@bjut.edu.cn) 


\begin{tabular}{|ll|}
\hline Nomenclature \\
Variables, parameters and indices \\
$E_{\text {Total }} \quad$ Total energy consumption, the sum energy consumption of the \\
$E_{T}$ & cooling plant and the terminal \\
$E_{C P}$ & Terminal energy consumption \\
$E_{\mathrm{TA}}$ & Cooling plant energy consumption \\
$E_{\mathrm{TN}}$ & terminal HVAC system energy consumption \\
$T_{d b}$ & all other terminal systems except HVAC energy consumption \\
$T_{d p}$ & Dew point temperature \\
$L_{C C}$ & Low cloud cover \\
$S P$ & Surface pressure \\
$W D$ & wind direction \\
$P_{T}$ & Total passenger flow \\
$P_{D}$ & Departing passenger number \\
$P_{A}$ & Arrival passenger number \\
$T_{w s}$ & Supply water temperature \\
$T_{w r}$ & Return water temperature \\
$T_{S F}$ & supply air temperature of AHU \\
$T_{i}$ & indoor temperature \\
$f_{S}$ & supply fan frequency \\
$f_{P}$ & exhaust fan frequency \\
$C_{C O 2}$ & CO ${ }_{2}$ concentration \\
$\bar{x}$ & The average \\
$\mathrm{S}$ & Standard deviation \\
$r$ & correlation coefficients \\
$\mathrm{P}$ & p-value \\
$\mathrm{R}^{2}$ & Coefficient of determination \\
$Y_{0}, A, t$ & Regression coefficients \\
$\mathrm{Q} 1$ & Lower quartile, 25th percentile \\
$\mathrm{Q} 3$ & Upper quartile, 50th percentile \\
$R_{1}$ & Quartile range, $Q_{3}-Q_{1}$ \\
Abbreviation & \\
$\mathrm{CV}$ & Coefficient of variation \\
$\mathrm{SD}$ & Standard deviation \\
$\mathrm{HVAC}$ & Heating, ventilation and air-conditioning \\
$\mathrm{AHU}$ & Air-conditioning units \\
$\mathrm{FCU}$ & Fan coil unit \\
$\mathrm{VRF}$ & Variable refrigerant volume \\
$\mathrm{COP}$ & Coefficient of Performance \\
\hline & \\
\hline
\end{tabular}




\section{Introduction}

With China's urbanization and continual development, the number of civil airports increases rapidly from 175 in 2010 to 218 in 2016 . In the $13^{\text {th }}$ Five-year Plan for China Civil Aviation published by The Civil Aviation Bureau in Feb 2017, 260 civil airports will be built by 2020 [1]. Compared with conventional civil buildings, airport terminals are characterized by enormously high and open spaces enclosed mainly with glazing system. These buildings handle a large number of passengers and need to maintain operation for an extended duration every day. All these factors lead to very high HVAC energy consumption [2]. Civil Airport Terminal Green Performance Investigation Report published by Civil Aviation Bureau in 2017 showed that the energy consumptions including terminal buildings and cooling plants were 129-281 $\mathrm{kWh} /\left(\mathrm{m}^{2} \cdot \mathrm{a}\right)$ with an average value of $180 \mathrm{kWh} /\left(\mathrm{m}^{2} \cdot \mathrm{a}\right)$. In similar climate conditions, the maximum energy consumption can be $50-100 \%$ higher than the average value, which means there is a high potential for energy saving [3]. The average energy consumption is about 2.9 times that for non-airport public buildings, which is $61.96 \mathrm{kWh} /\left(\mathrm{m}^{2} \cdot \mathrm{a}\right)$ [4]. Among the total airport energy consumptions, 41.2-62.9\% are consumed by the HVAC systems, which are in the range of 73.4 to $121.7 \mathrm{kWh} /\left(\mathrm{m}^{2} \cdot \mathrm{a}\right)$. In countries outside China, the HVAC energy consumption is about 80\% [5] for Adnan Menderes Airport and 86\% [6] for Soekarno-Hatta Menderes Airport. Therefore, it is important to understand the contributing factors to airport energy consumption, especially HVAC energy consumption in order to reduce total airport energy consumption, cut carbon emission and protect environment [7].

In recent years, there have been many studies on the total energy consumption and HVAC system energy consumption in airports at home and abroad using energy consumption predictions, computer simulations, on-site questionnaire investigations and field testing [3,811]. In energy consumption prediction field, scholars were more concerned about how to improve the accuracy of prediction. Chen et al. proposed a mixed method by combining neuronetwork and grey method, which can achieve a prediction accuracy of 93\% $[12,13]$. Huang et al presented a hybrid model predictive control (HMPC) scheme, which combined the classical approach with a neural network feedback linearization method. Compared with existing control methods, this method has higher prediction accuracy in terms of energy saving and cost saving [14]. With building energy simulation, researchers intend to support rational use of energy and make recommendations for energy saving measures. Balaras et al. simulated airport terminal energy consumption based on on-site measurement of indoor thermal environment and 
1 passenger survey, and their study showed a potential to achieve 15-35\% energy saving [15]. Chen et al. simulated an airport HVAC system by Energy Plus software. After verification against measured data, the simulation showed that by lowering the supply air temperature from $15^{\circ} \mathrm{C}$ to $12^{\circ} \mathrm{C}$, the total energy consumption can be reduced by $4-6 \%$ [16]. Fang et al. applied Energy Plus simulated hourly operation data throughout one year to obtain the Coefficient of Performance (COP) value of the chiller by clustering and regression of these data, which can be used to optimize the chiller operation [17]. Previous studies have also been performed on the impact of operating parameters such as supply air temperature, air flow rate, supply vane angle, etc. on energy consumption, based on the studies, guidance was provided on the selection of the optimization method to improve the operation [18-19]. In all these studies, energy consumption predictions and simulations require a large number of boundary conditions, which are mainly from field testing or operating data. And the results of predictions or simulations need to be verified against actual measurement or operating data [20-23]. All researches listed above have used site measurement or operating data from real airport terminals, but these data either referred to a specific location of an airport or limited to a short time duration. It is well known that energy consumptions vary significantly with locations and seasons [24], and a study needs to track a full building for at least one year to provide a complete profile of the building energy consumption characteristics.

Airport energy consumptions are strongly correlated to the overall passenger number and flows [3]. There have been many studies on airport passenger flows. Liu et al, simulated the dynamic distribution of airport passengers with on-site investigation as input data. Their result showed that the passenger density exceeded the design value in only $3.6 \%$ of total duration. The maximum usage ratio of departure floor was only 54.8-64.4\%, and the maximum actual demand of cooling load for primary air $\left(25 \mathrm{~W} / \mathrm{m}^{2}\right)$ was obviously lower than the design value $\left(47 \mathrm{~W} / \mathrm{m}^{2}\right)$, which means the energy consumption of the HVAC systems in airports can be significantly reduced if the amount of mechanical outdoor air can be adjusted with variation of actual occupancy rates [25]. Furthermore, Liu et al, investigated the passenger flow in main public areas of a Chinese hub airport terminal in typical three months of three different seasons. The results showed various areas in the terminal building displayed very different passenger flow characteristics [26]. Abdulhameed et al. presented and appraised fuzzy control strategies for reducing energy consumptions, and the inputs were the time schedule for arrival and departure of passenger planes as well as the expected number of passengers during each flight, zone illuminance and external temperature [27]. 
2 As a summary of the literature review, to better understand the energy consumption of airport terminals requires long-term monitoring of their operations, including meteorological data, mechanical system data and passenger data. And as far as the authors are aware, this paper is the first to present multiple-year operation data. Data including terminal and cooling plant energy consumption, indoor temperature, passenger flow, meteorological parameters and air conditioning unit parameters etc. were collected for Nanning Wuxu International Airport Terminal 2 from 2016-2019. Passenger flow patterns were also established based on the flight schedule in these years. Data analysis was performed to identify the airport terminal energy distribution pattern. Then, clustering analysis and correlation analysis were performed to find out the main factors influencing energy consumption. A model was built by regression analysis for the prediction of each categories of energy consumptions based on monthly values of major influencing factors. This study is expected to provide valuable information to the design and operation of airport terminals by refining the energy consumption simulation and prediction models.

\section{Methodology}

This section describes the methodology for data collection and analysis. The types of data were introduced following an introduction to the building. A statistical analysis was first performed to obtain the distribution pattern of each data set, followed by a cluster analysis to filter the main parameters. Correlation analysis was performed to identify the independent parameters and regression analysis was finally adopted to establish the equations for the prediction of energy consumptions. In this paper, all data analyses were carried out in Origin2019 (Origin Lab Inc., Massachusetts, USA).

\subsection{Building Description}

This study was based on the Nanning Wuxu International Airport Terminal 2, thereafter simplified as Nanning Airport. Nanning is located in south China with a climate characterized by hot summer and warm winter. According to China design code [28] the HVAC system needs to consider only cooling load in summer. The Nanning Airport was designed to accommodate 16.0 million passengers by 2020 with a total floor area of $183800 \mathrm{~m}^{2}$ consisting of three 
1 aboveground floors and one basement floor. The third floor includes a departure hall, security check area, waiting areas adjacent to boarding gates plus retails and offices. The second floor is for domestic arrival, international arrival, transfer and offices. The ground floor accommodates luggage handling plant room, luggage claim hall, reception hall plus offices and plant rooms. The basement is mainly plant rooms and utility tunnels.

This building was put in operation in September 2014. An independent cooling plant was built near the end of the west pier to provide cooling source for the terminal. An overview of the terminal is shown in Figure 1.

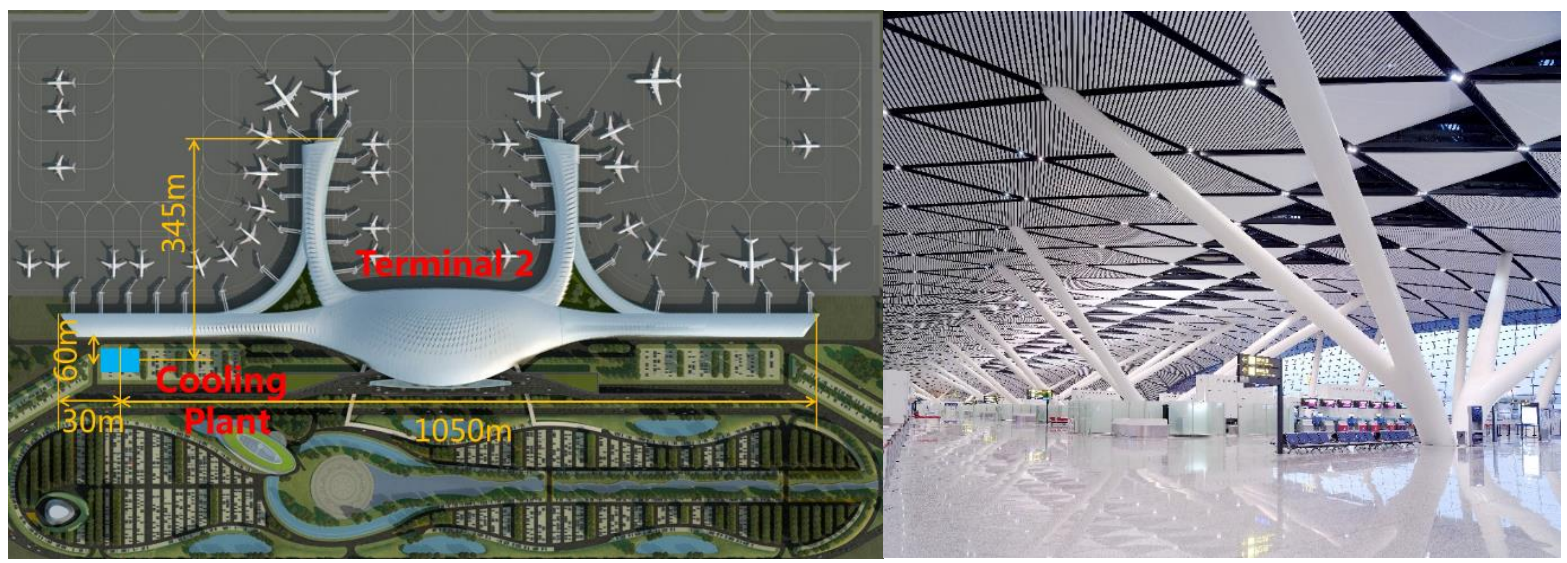

(a) Site plan

(b) Check-in hall

Fig. 1. The Nanning Airport Terminal 2

The environmental standards for the large space area are set as air temperature $26{ }^{\circ} \mathrm{C}$, relative humidity $55 \%$, fresh air volume $25-30 \mathrm{~m}^{3} /(\mathrm{h} \cdot \mathrm{p})$, indoor wind speed $0.2 \mathrm{~m} / \mathrm{s}$ and an air filtration standard F7. The cooling plant at the end of the west pier holds three 2100 RT centrifugal chillers, one 1000 RT centrifugal chiller, and the corresponding primary cold-water pumps and cooling towers to provide air conditioning cold sources for the terminal. The terminal air conditioning water system is a secondary pump system with secondary pump set located in the terminal building. Different HVAC terminal systems were adopted depending on space characteristics. The main public large space area uses regional variable air volume all air system (AHU, 90\% capacity), and the ordinary office room uses the fan coil unit plus the fresh air system (FCU, 10\% capacity). The HVAC terminal equipment on the third floor is shown in Figure 2.A total of 111 air-conditioning units (AHU-1F-A01, A05, C03, C05 etc.) are installed to provide a total air volume of 2.27 million $\mathrm{m}^{3} / \mathrm{h}$, with 835 fan coil units.

The terminal was divided into six zones as marked by dashed lines in Figure 2, each served by 
1 a substation thus allowing the regional energy consumption to be recorded daily. The energy of

2 the cooling plant was measured by the substation outside the terminal. A flow meter and a temperature sensor are installed on the supply and return water main pipe of the cooling plant

4

5 to measure the flow rate of the water system and the temperature of the supply and return water. The terminal air conditioning unit measures the fresh air temperature, supply air temperature, return air temperature, return water temperature, supply fan frequency, exhaust fan frequency, $\mathrm{CO}_{2}$ concentration, etc.

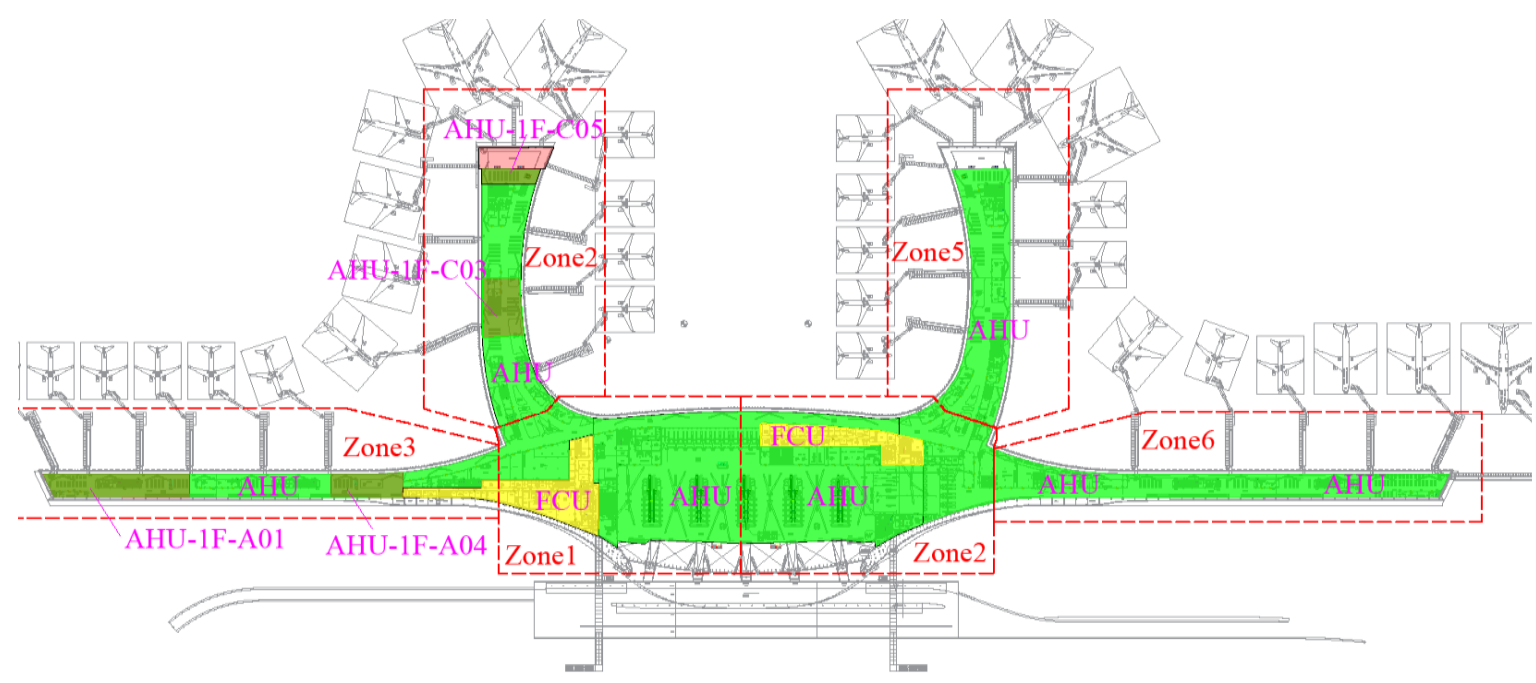

Fig. 2. The HVAC System of Nanning Airport Terminal 2

\subsection{Operating Data Collection}

Airports have strict operation requirements and keep accurate recording of flight information, communication facilities operation, and security preventions. The data collected in this article are from the airport's operating records from 2016-2019. Details are shown in Table 1.

Table 1 Operating Data

\begin{tabular}{lll}
\hline Item & Description & $\begin{array}{l}\text { Frequency } \\
\text { and duration }\end{array}$ \\
\hline Terminal & Energy consumption of all terminal facilities, categorized & Daily from \\
energy & as office, roof lighting, advertisement, commercial, & $2016-2019$ \\
consumption & HVAC system, MEP rooms, low-voltage electrical & Hourly in \\
& system, lift system, boarding gates. & 2017 \\
Cooling plant & Energy consumption of all cooling plant facilities & Daily from \\
energy & including chillers, cold-water pumps, cooling towers and & $2016-2019$ \\
consumption & lighting & Hourly in \\
& & 2017
\end{tabular}


Meteorological Dry bulb temperature, dew point temperature, low cloud data $\left(22^{\circ} 36\right.$ 'n cover, surface pressure, wind direction $108^{\circ} 10$ 'e)

Passenger data Total passenger flow, Departing passenger number and Arrival passenger number

Terminal Energy meter readings, including water flow, supply cooling data HVAC system parameter water temperature and return water temperature. Fresh air temperature, supply air temperature, indoor temperature, return water temperature, supply fan
Hourly from 2016-2019

Hourly from 2016-2019

Hourly in 2017

Hourly from 2016-2017

frequency, exhaust fan frequency and $\mathrm{CO}_{2}$ concentration

3

4

\subsection{Statistical analysis}

Table 1 lists a large amount of data and some of them are repeating. For example, the fresh air temperature of the HVAC system theoretically should be the same with dry bulb temperature neglecting the measurement errors and the influence of measuring locations. Some parameters such as the return water temperature of AHU represent individual terminal and provides little information on system performance. After initial filtering, the following parameters are included in the current analysis: total energy consumption, terminal energy consumption $\left(E_{T}\right)$, Cooling plant energy consumption, supply water temperature, return water temperature, dry bulb temperature, dew point temperature, low cloud cover, pressure, wind direction, total passenger flow, departure passenger, arrival passenger, indoor temperature, supply air temperature, supply fan frequency, exhaust fan frequency and $\mathrm{CO}_{2}$ concentration.

Statistical methods were used for the analysis of the operating data. The following concepts are commonly used in statistics: sum, frequency count, mean $(\bar{x})$, standard deviation (s), coefficient of variation $(\mathrm{CV}=\mathrm{s} / \bar{x})$, where $\mathrm{CV}$ is used to check the dispersion degree of the data. When $\mathrm{CV}$ is less than $10 \%$, it is considered the sample is stable with little variation [29]. Before data analysis, a Kolmogorov-Smirnov test was performed to check if the data set follows normal distribution. If so, t-test will be performed to check if two independent samples have significant variation. When $\mathrm{P} \leq 0.05$, it is considered they have significant variation, otherwise they are considered to show little variation. When the data set does not follow normal distribution, a Kolmogorov-Smirnov test with two independent samples will be performed to check if the two local samples have significant variation.

\subsection{Cluster analysis}


1 A cluster analysis was performed to reduce the number of independent variables to be included

in further analysis. The principle was to categorize parameters according to their similarities and all variables with high similarity could be treated as one parameter [30]. Assuming a total of $\mathrm{n}$ parameters initially, hierarchical clustering was adopted and median method was used to calculate the Euclidian distance between any two parameters. The two with the smallest distance were combined as one new category and the rest remained to obtain n-1 parameters. This operation could be repeated until all potential target parameters had been combined. Due to the large difference between the maximum and minimum value of each parameter, the median method was used for distance calculation.

\subsection{Correlation analysis}

Correlation coefficient was commonly used to describe the linear relationship between parameters without giving too much information on the internal logic among the parameters. Whereas partial correlation coefficient can calculate the linear correlation among two variables while removing the impact of other parameters. When the sample follows normal distribution, Pearson correlation analysis was performed, otherwise Spearman correlation analysis was performed. The correlation between two variables is defined as non-relevance when the partial correlation coefficient is $0-0.09$, weak relevance when it is $0.1-0.3$, medium relevance when it is 0.3-0.5 and strong relevance when it is 0.5-1.0 [31]. Positive partial correlation coefficient value means positive correlation, and vice versa.

Hourly data was recorded for all parameters in 2017 whereas for other years, the energy consumptions were recorded daily as shown in Table 1. Therefore, a comprehensive analysis including both simple correlation analysis and partial correlation analysis were performed to the hourly data in 2017 first. Then partial correlation analysis was performed to the daily and monthly data from 2016-2019 and compared to the result from 2017. The purpose of the analysis was to demonstrate the accuracy of the daily and monthly energy consumption data because daily and monthly energy consumption were more commonly used in practice.

\subsection{Regression Analysis}

On the basis of clustering and correlation analysis, all factors that impose a major impact to the total energy consumption or its sub-items could be determined. Then, the approximate 
1 functional relationship between these factors and the energy consumption sub-items could be obtained by regression analysis. The sum of these sub-items gave preliminary prediction of the total energy consumption. The graph and data analysis software Origin2019 (Origin Lab Inc., Massachusetts, USA) was used to obtain the optimal-fit model. The significance of the regression model was determined by $\mathrm{F}$ test of the variances. When $\mathrm{P}$ value was less than or equal to 0.05 in $F$ test, the regression was considered significant. For multiple linear regressions, $\mathrm{t}$ test of regression coefficient was performed. When $\mathrm{P}$ value was less than or equal to 0.05 , a linear relationship between independent variable and dependent variable was considered. The quality of the regression analysis can be checked by coefficient of determination $\left(\mathrm{R}^{2}\right)$ and Adjusted $\mathrm{R}^{2}$. The curve was considered to fit the variables extraordinary well when $\mathrm{R}^{2}$ was closer to 1 , and reasonably well when $\mathrm{R}^{2}$ was above 0.8 [32].More details about the statistical analysis theories can be found in literature [33-35].

\section{Results}

\subsection{The distribution Characteristics of Energy Consumption}

- Temporal distribution characteristics

The terminal energy consumption, cooling plant energy consumption, passenger flow, meteorological parameters (dry bulb temperature and dew point temperature), indoor temperature and $\mathrm{CO}_{2}$ concentration from 2016 to 2019 are presented in Figure 3-6. For indoor temperature and $\mathrm{CO}_{2}$ concentration, the average values in large space of the terminal were used.

It can be seen from Figure 3 (a) and 4 (a) that the energy consumptions of the terminal building increased over the years. The total energy consumption $\left(E_{\text {Total }}\right)$ increased by $4.1 \%, 7.2 \%$ and 7.3\% from 2017-2019. The energy consumption of the cooling plant $\left(E_{C P}\right)$ increased by $1.0 \%$, $5.5 \%$ and $5.8 \%$ correspondingly. The increase rates of the terminal building are higher than the cooling plant. The $E_{\text {Total }}$ displayed an obvious yearly cyclic pattern with peak value in summer and off-peak values in winter. Both peak values and off-peak values increased slightly from 2017-2019.

The departure and arrival passengers also increased over the years. The departure passengers 
$1 \quad\left(P_{\mathrm{D}}\right)$ increased by $19.9 \%, 6.9 \%$ and $2.8 \%$ from 2017 to 2019 while the arrival passengers $\left(P_{\mathrm{A}}\right)$ increased by $20.9 \%, 10.1 \%$ and $6.1 \%$. The total passengers $\left(P_{\mathrm{T}}\right)$ increase rates were $20.4 \%, 8.5 \%$ and $4.4 \%$, which is obviously not in a linear relationship with the $E_{\text {Total }}$. Therefore, it requires further analysis to identify their relevance.

The monthly outdoor dry bulb temperature $\left(T_{d b}\right)$ and dew point temperature $\left(T_{d p}\right)$ are shown in Figure 5. In the figure, some obvious outliers were observed, for which the lower truncation point was defined as $\mathrm{Q}_{1}-1.5\left(\mathrm{Q}_{3}-\mathrm{Q}_{1}\right)$ where $\mathrm{Q}_{1}$ is the 25 th percentile and $\mathrm{Q}_{3}$ is the 75 th percentile. Kolmogorov-Simonov test was carried out on the average monthly data of 2016 and 2017, which showed that both followed normal distribution. The $t$ test gave a P Value of 0.975 , which was far larger than 0.05 , indicating no significant difference between these two parameters. Same conclusions can be drawn when comparing the input from other years. Comparing the mean value, the standard deviation (SD) and CV (Coefficient of variation) values of the daily average temperature from all years showed that the mean values were nearly the same. SD and $\mathrm{CV}$ values were also similar from year. The analysis was repeated to the distributions of indoor temperature $\left(T_{\mathrm{i}}\right)$ and indoor $\mathrm{CO}_{2}$ concentration $\left(C_{\mathrm{CO} 2}\right)$ as shown in Figure 6 . The $\mathrm{CV}$ values of indoor temperatures were $0.2,0.15,0.15,0.15$ and the $\mathrm{CV}$ value of indoor $\mathrm{CO}_{2}$ concentrations were $0.02,0.01,0.02,0.01$. Again, the average values, SD and CV values were nearly the same over the years. In summary, the four parameters, dry bulb temperature and dew point temperature, indoor temperature and indoor $\mathrm{CO}_{2}$ concentration remain basically unchanged from one year to another and when necessary, the data from one specific year can be used for further study.

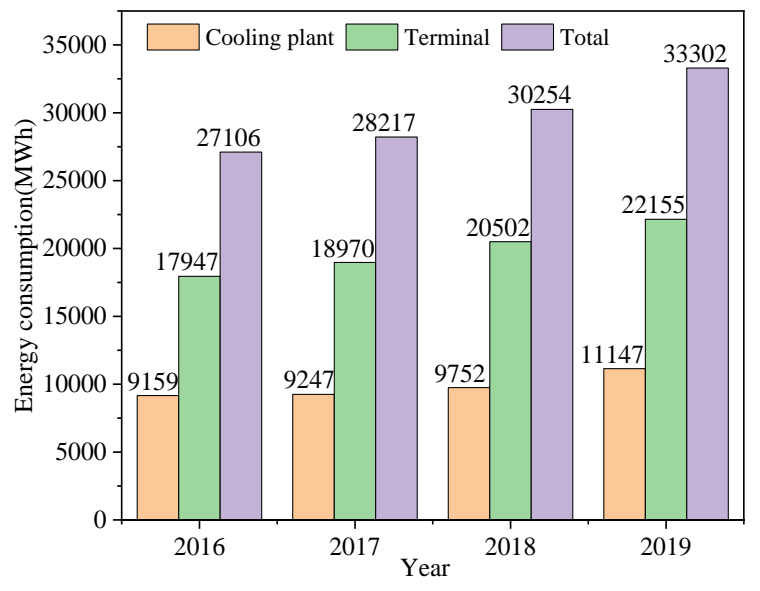

(a) Annual energy consumptions

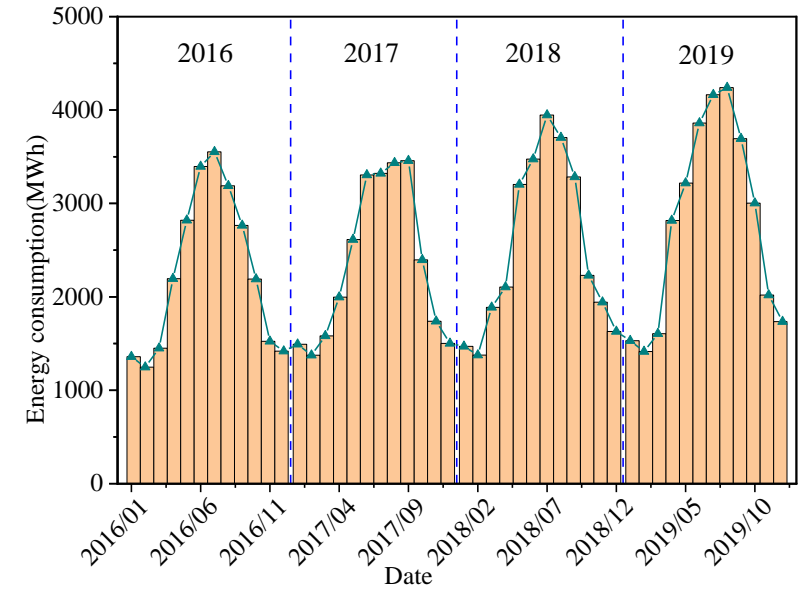

(b) Monthly total energy

Fig. 3. Energy consumption in 2016-2019 


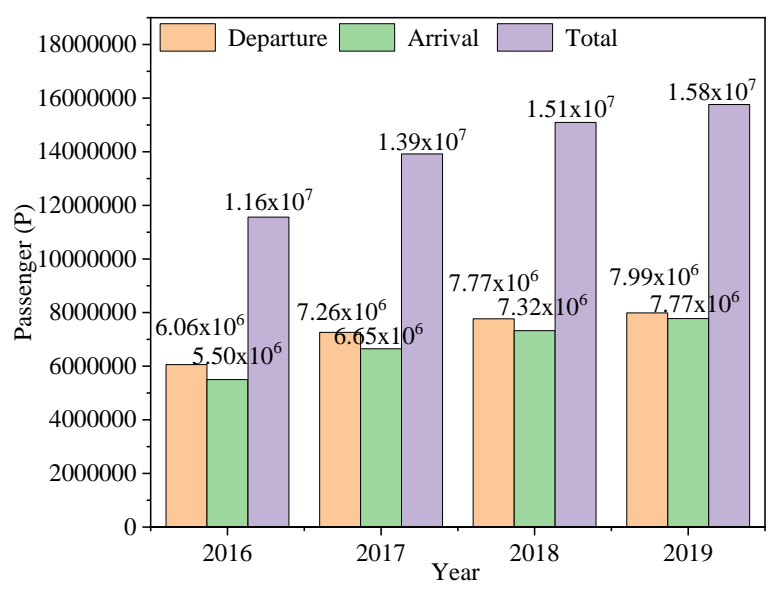

(a) Annual passenger flow

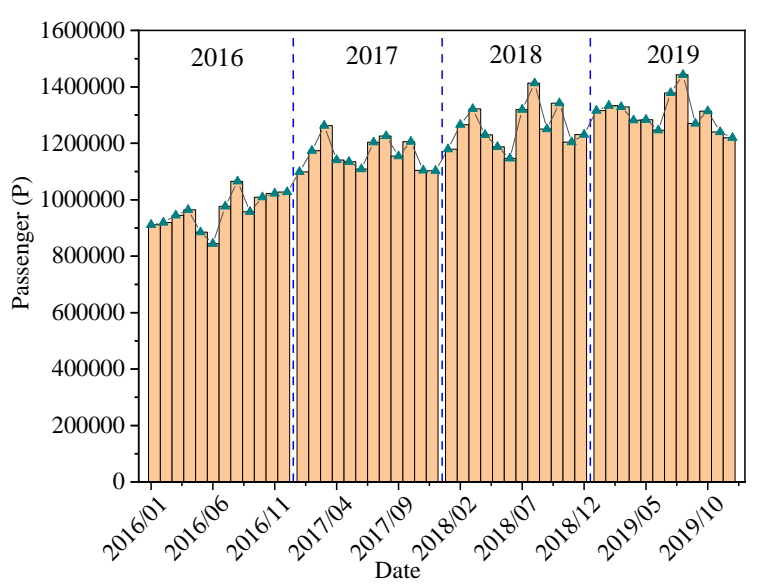

(b) Monthly total passenger flow

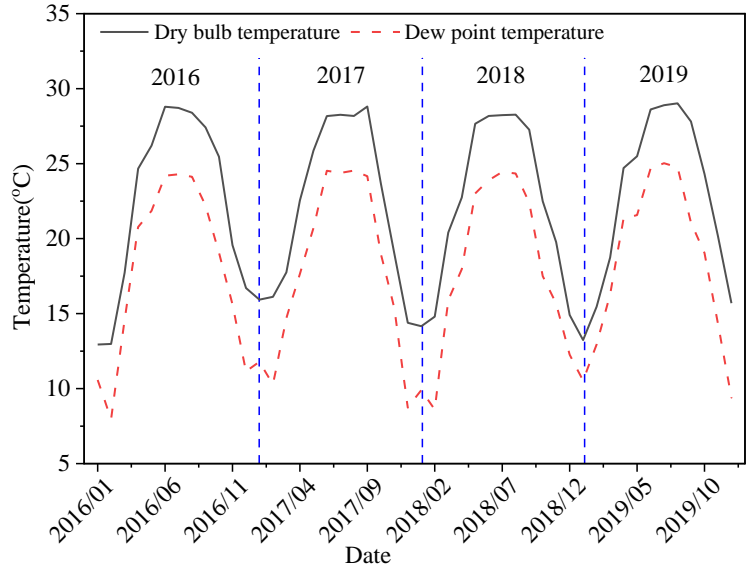

(a) Monthly average temperatures

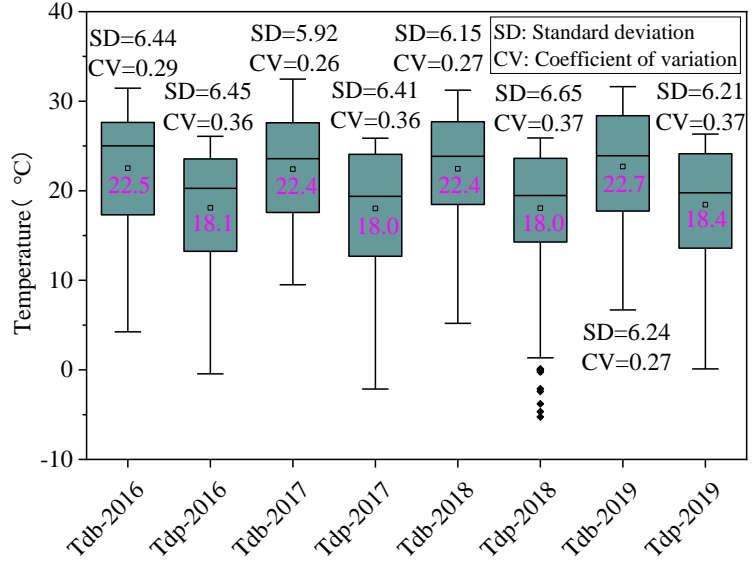

(b) Boxplots of daily average temperatures

Fig. 5. Outdoor temperature

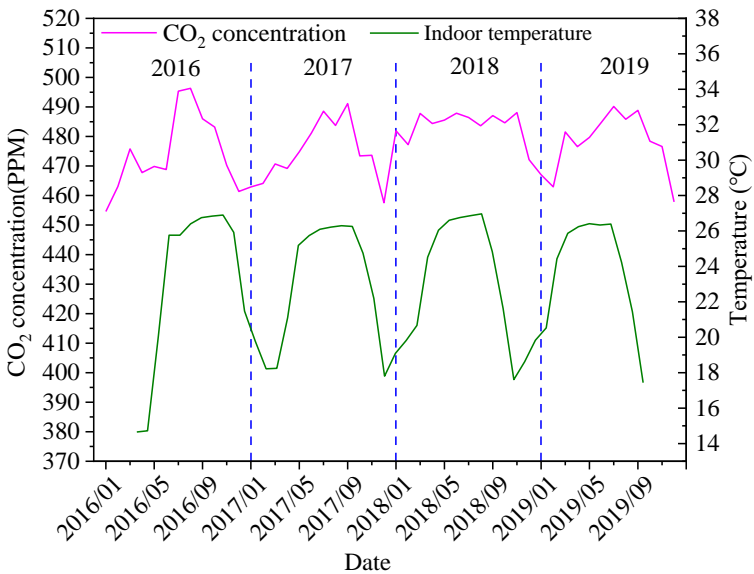

(a) Monthly average values

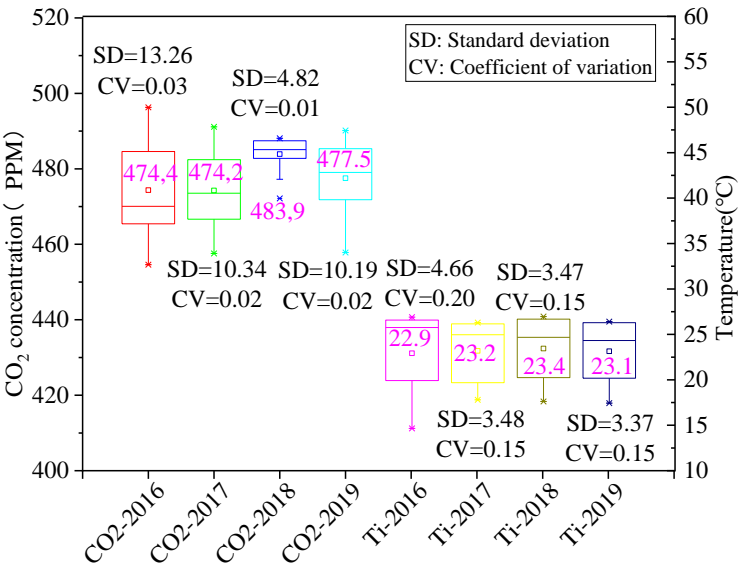

(b) Boxplots of daily average values

Fig. 6. Indoor temperature and $\mathrm{CO}_{2}$ concentration in 2016-2019 
2 The energy consumption of all terminal sub-items were also analyzed for four years, as shown in Figure 7. Except for the advertising energy consumption, all other sub-items basically

4 increased from 2016 to 2019. Nevertheless, their proportions maintained stable. The cooling plant remained as the largest single source of energy consumption, whose energy consumption constituted $31.8 \%-33.8 \%$ of the total energy consumption, followed by the terminal HVAC system, with a percentage of $15.9 \%-17.4 \%$. These two items (representing the total energy consumption of the HVAC system) accounted for $48.6 \%-50.4 \%$ of the total energy consumption of the terminal. Therefore, it is of great significance to study the energy consumption of the HVAC system for reducing the total energy consumption of the terminal.

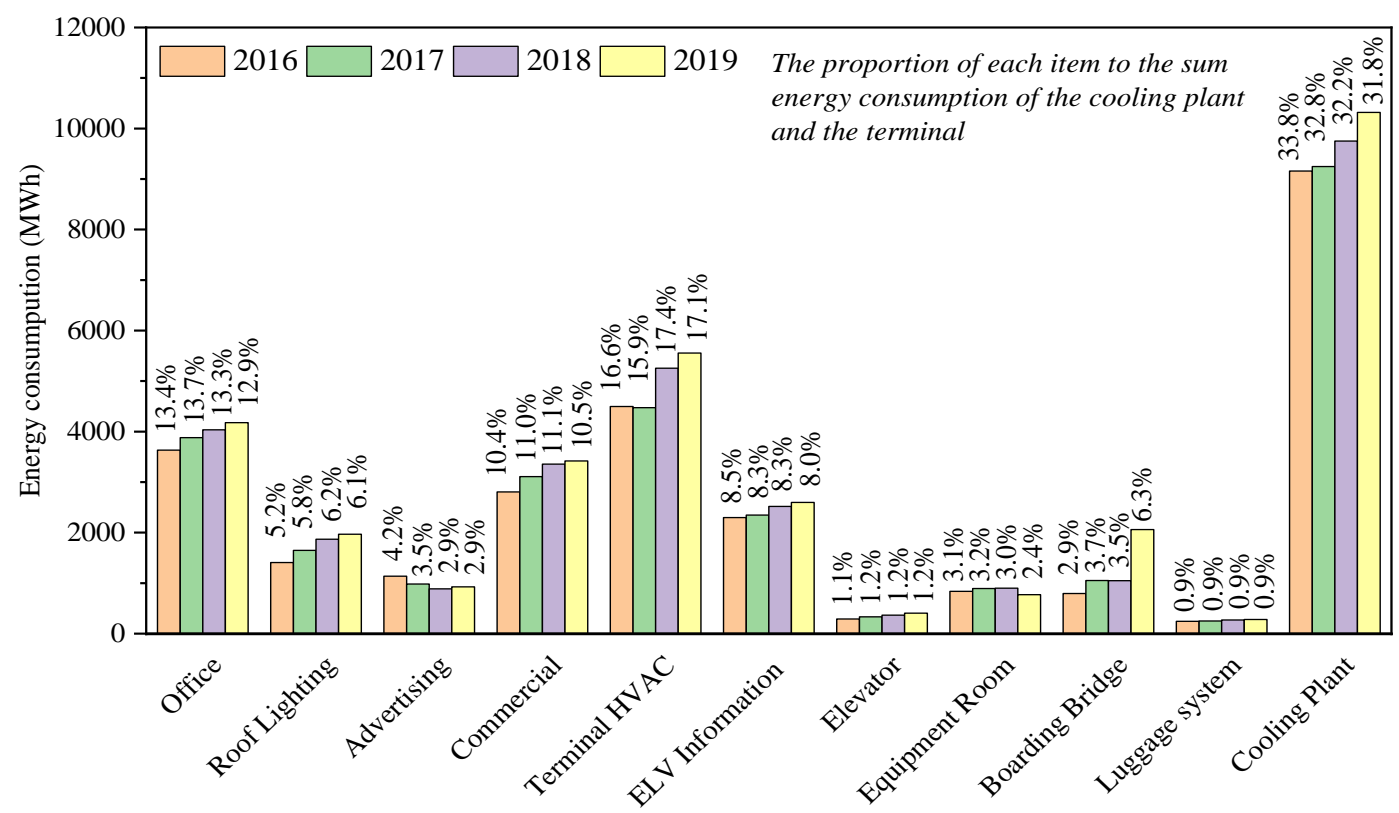

Fig. 7. Classification of terminal energy consumption

The above analysis demonstrated again that the system energy consumption followed a similar pattern every year. Therefore, the data in 2017 was used as an example to study the temporal distribution characteristics of the terminal energy consumption, which was divided into two categories of the electricity consumption by the HVAC system $\left(E_{\mathrm{TA}}\right)$ and the electricity consumption by all other systems $\left(E_{\mathrm{TN}}\right)$. Their distributions and statistical characteristics are shown in Figure 8, where the $E_{\mathrm{TN}}$ show little fluctuation about the daily average value of 38.9 $\mathrm{MWh}$, the $E_{\mathrm{TA}}$ showed much higher variation from the daily average value of $12.3 \mathrm{MWh}$. The cooling plant energy consumption $\left(E_{\mathrm{CP}}\right)$ is also shown in the figure, to provide a complete profile. As $E_{\mathrm{CP}}$ occurred only in the air-conditioning season, their daily values fluctuated 
1 dramatically around the average value of $25.3 \mathrm{MWh}$.

2

3 The three energy consumptions showed standard deviations (SD) of 21.24, 3.3 and 2.17 and 4 variation coefficients (CV) of 0.96, 0.27 and 0.06 in 2017, as shown in Figure 8 (b). The CVs

5 of the $E_{\mathrm{CP}}$ and $E_{\mathrm{TA}}$ were 16 times and 4.5 times that of the $E_{\mathrm{TN}}$. Analysis to the data in 2016,

62018 and 2019 showed similar pattern that $E_{\mathrm{TN}}$ had an annual CV less than $10 \%$.

7 In conclusion, the daily electricity consumption by all other systems in the terminal maintained 8 nearly constant all the year and could be represented by yearly average value. Their proportion 9 in total energy consumption remained around $50 \%$ in all years.

10

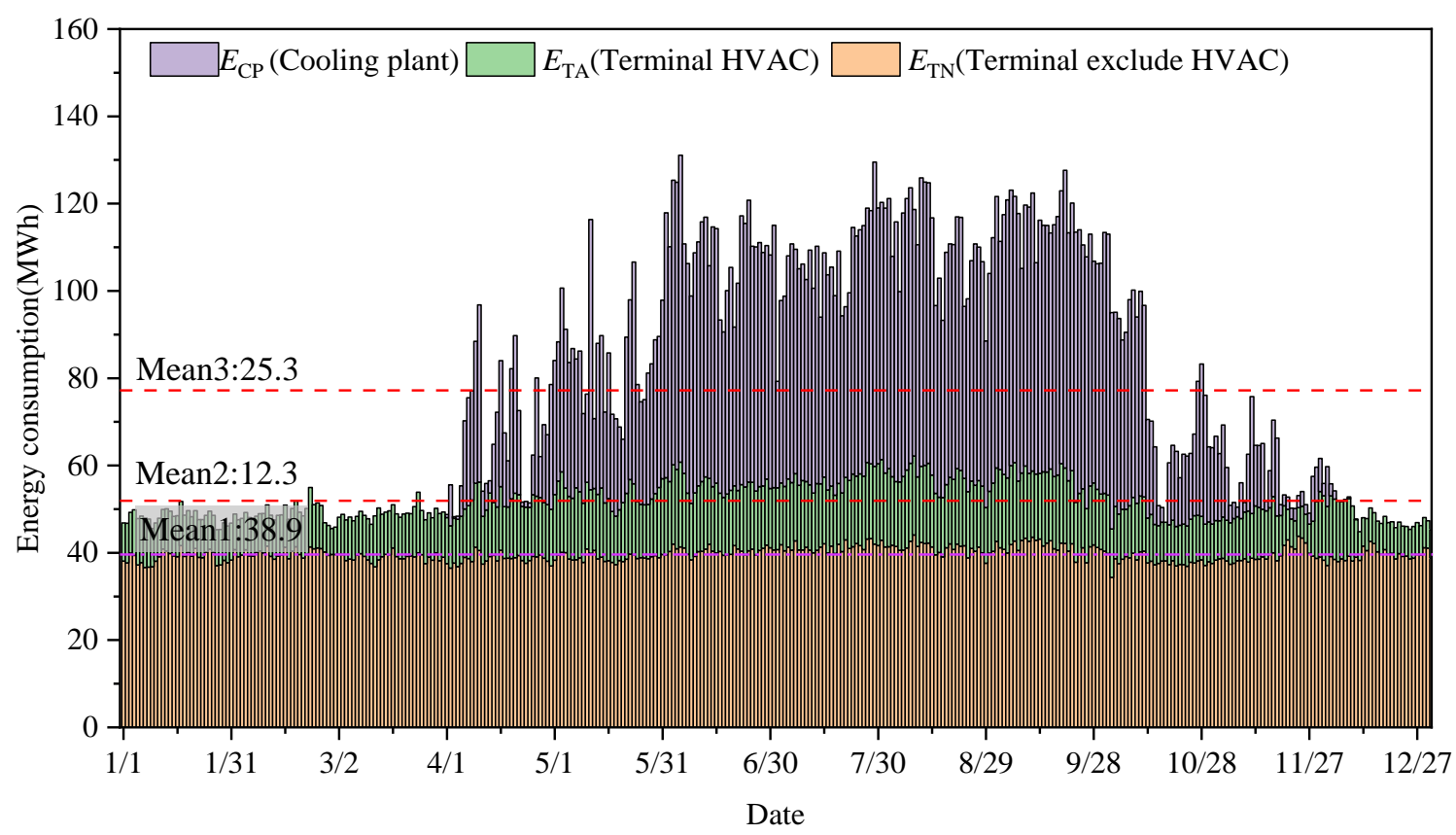

11

12

(a) Annual in 2017 


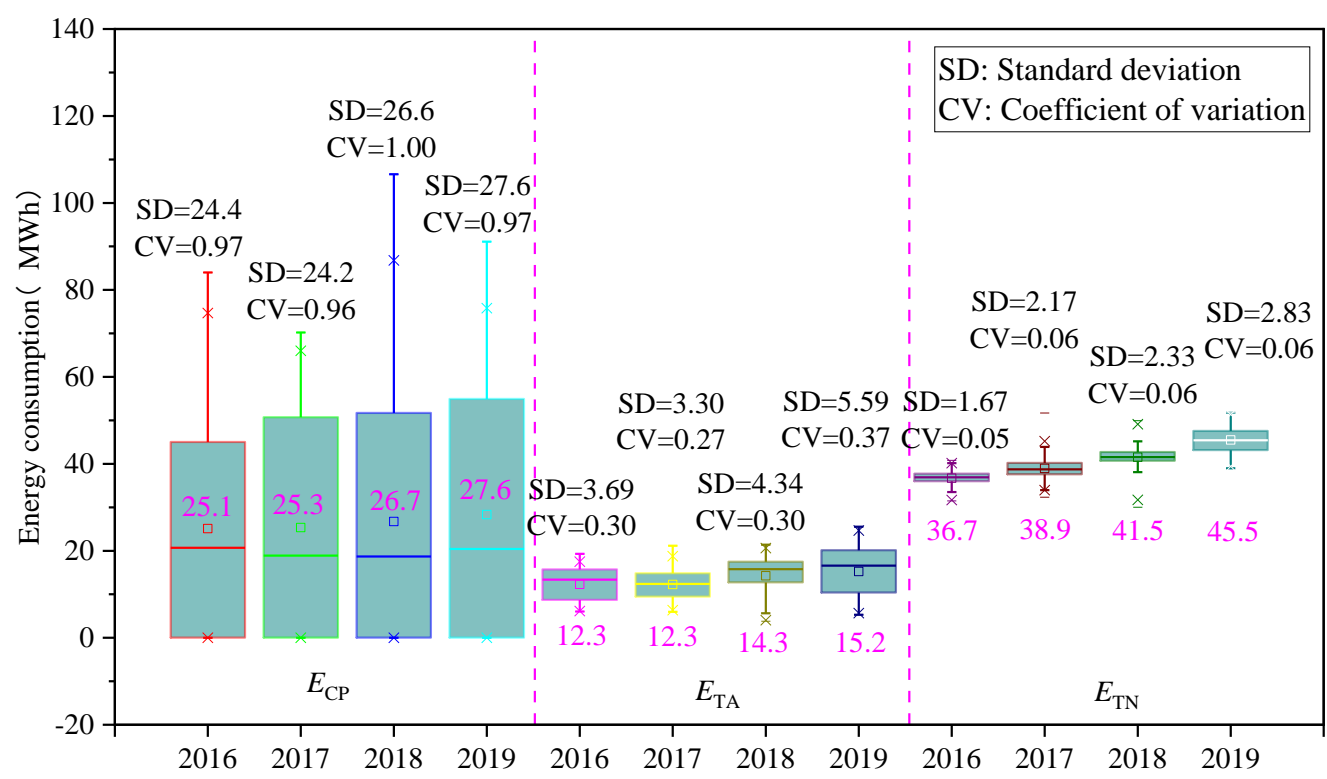

(b) Box plot in 2016-2019

Fig. 8. Daily distribution of energy consumption

- Spatial distribution characteristics

The distribution of $E_{\mathrm{TA}}$ and $E_{\mathrm{TN}}$ in different zones are analyzed in this section. Again, using the data in 2017 as an example, the distribution curves in different regions are shown in Figure 9. The CVs for $E_{\mathrm{TA}}$ in different areas were 0.17-0.50. Comparing against the annual value of 0.27 for the whole building, $E_{\mathrm{TA}}$ showed non-uniform distribution with the change of location.

The CVs for $E_{\mathrm{TN}}$ energy consumption were $0.05-0.09$, which was close to the annual value of 0.06 of the whole building. It indicated that the distribution of $E_{\mathrm{TN}}$ showed little variation with the change of location. This could be partially contributed to the nature that the $E_{\mathrm{TN}}$ was not directly affected by the outdoor Meteorological parameter, but more related to passenger flow.

The $E_{\mathrm{TA}}$ and $E_{\mathrm{TN}}$ per floor area are shown in Figure 9 (c). The $E_{\mathrm{TA}}$ per floor area are higher in Zone 1,2,3 and 6. For Zone 3 and 6, this could be explained by the VIP services that adopted variable refrigerant flow (VRF) air-conditioning system whereas other areas had only air conditioning terminal equipment. Zone 1 and 2 are the main activity areas for passengers such as the main check-in hall, security check hall, baggage claim hall and arrival hall, etc., which suggested a relation between high energy consumption per floor area to active human activity. 
1 The absolute value of $E_{\mathrm{TN}}$ and values per floor area were both location dependent. It is 2 particularly worth attention that Zone1 and 2 had highest absolute values, but lowest values per 3 floor area, which means the energy consumptions of these facilities are not uniformly 4 distributed. Therefore, when calculating the air-conditioning load, the heat generated by 5 facilities shall be location and function dependent.

6

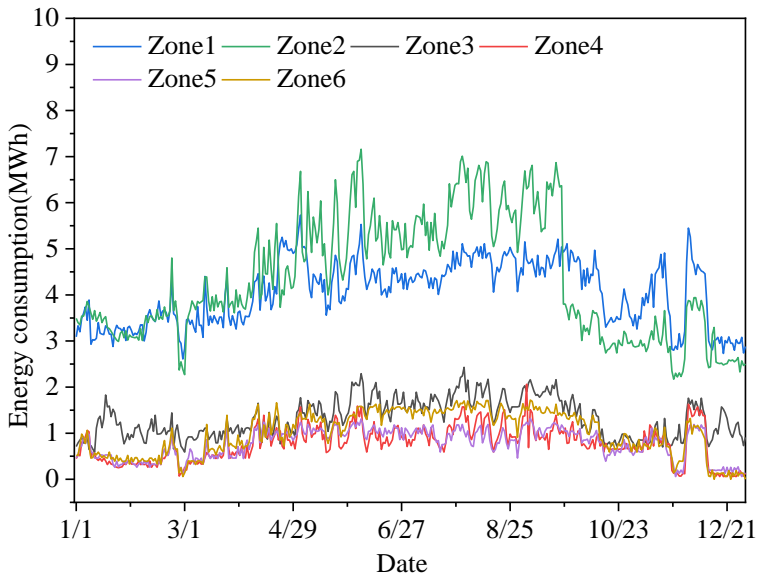

(a) Terminal HVAC system $\left(E_{\mathrm{TA}}\right)$

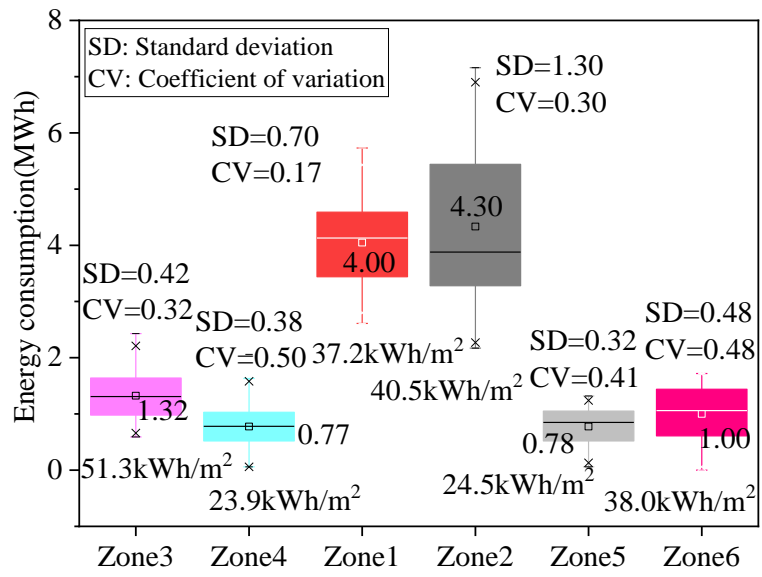

(c) $E_{\mathrm{TA}}$ boxplots

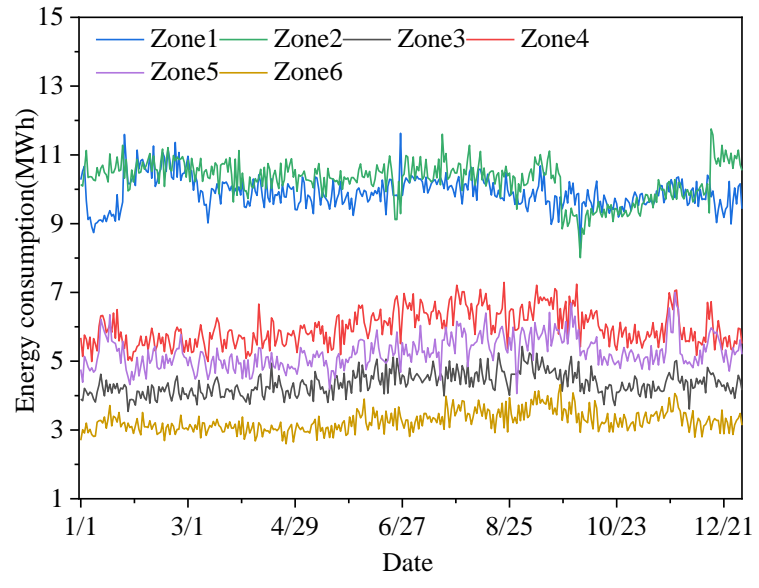

(b) Terminal exclude HVAC system $\left(E_{\mathrm{TN}}\right)$

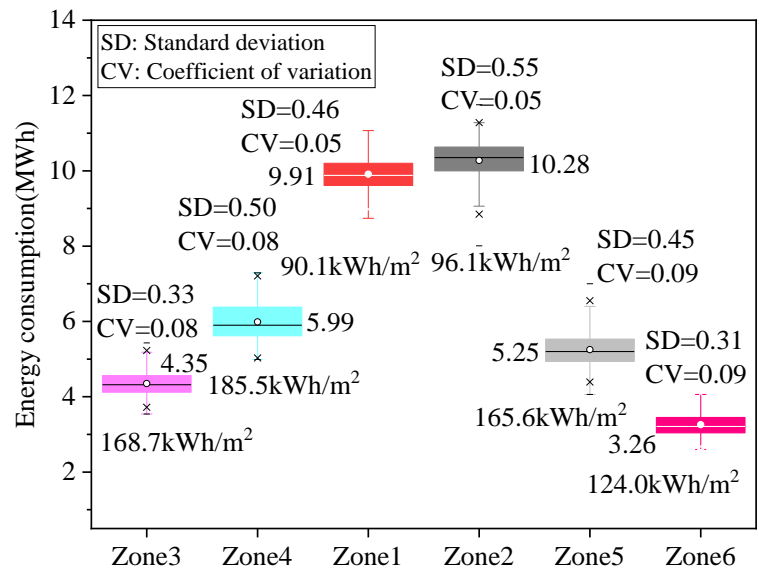

(d) $E_{\mathrm{TN}}$ boxplots

Fig. 9. Daily distribution of energy consumption in different regions in 2017

In conclusion, the monthly mean values of terminal energy consumption, outdoor dry bulb temperature and dew point temperature follow normal distribution, and the distribution characteristics are similar from year to year. However, the monthly accumulative value of passenger flow increases with the years, which do not follow normal distribution. The energy consumption of the terminal shows uneven temporal and special distribution, therefore, when calculating the energy consumption, the influence of terminal location and time season should be considered. 


\subsection{Energy efficiency}

3

The energy consumption per floor area and per passenger were calculated and compared against the national standards [35-36]. In agreement with the national standard approach, the energy of the boarding gates was excluded[35]. The total annual energy consumptions per floor area were $143.1 \mathrm{kWh} / \mathrm{m}^{2}, 178.8 \mathrm{kWh} / \mathrm{m}^{2}, 158.9 \mathrm{kWh} / \mathrm{m}^{2}$ and $176.7 \mathrm{kWh} / \mathrm{m}^{2}$ from $2016-2019$, all lower than the average value of domestic airports in the same climate zone $236 \mathrm{kWh} / \mathrm{m}^{2}$ [3]. The total energy consumptions per passenger were $2.28 \mathrm{kWh} / \mathrm{P}, 1.95 \mathrm{kWh} / \mathrm{P}, 1.94 \mathrm{kWh} / \mathrm{P}, 1.93 \mathrm{kWh} / \mathrm{P}$ from 2016-2019, and the national standard threshold was $2.0 \mathrm{kWh} / \mathrm{P}$ [35]. Except for 2016, all other years met the threshold.

The HVAC system efficiency is defined in national standard as the total cooling energy consumption during air-conditioning season divided by the sum of the electricity consumption of the cooling plant and terminal HVAC system during air-conditioning season [35]. And the efficiency of the air-conditioning terminal unit (AHU, FCU) is defined as the cooling energy consumed by the air-conditioning terminal units divided by their electricity consumption. During the air-conditioning season of 2017, the total cooling load was 34488.57 MW and the terminal HVAC system energy consumption was $3572.96 \mathrm{kWh}$. The HVAC system efficiency could be calculated as 3.69, which was higher than the national standard threshold of 3.6 [35]. The efficiency of the air-conditioning terminal unit was 9.65, again, higher than the national standard threshold of 6.3 (90\% AHU threshold + 10\% FCU threshold) [35]. The above analysis shows the overall energy efficiency index of Nanning Airport met the national standard and the system performance was above the national average.

\subsection{Cluster analysis}

Cluster analysis was performed for the parameters studied and all categories of the energy consumptions in Figure 10. Using a similarity of $85 \%$ as a criterion, outdoor dry bulb temperature, indoor temperature and outdoor dew temperature could be classified as one category of temperature. The supply water temperature, return water temperature could be put in one category of water temperature. Total passenger flow and departure passenger flow could be put in one category. It would require the criterion for similarity to be lowered to $80 \%$ for all passenger flows to be combined in one category, which meant less similarity of the arrival 
1 passenger flow with the total passenger. Other parameters such as low cloud cover, surface pressure, wind direction, supply air temperature, supply fan frequency, exhaust fan frequency and $\mathrm{CO}_{2}$ concentration could be considered as independent parameters. Among all sub-items of energy consumptions, the total energy consumption and the cooling plant energy consumption showed high similarity.

The cluster analysis gave the representative parameters as outdoor dry bulb temperature in temperature category, supply water temperature in water temperature category and total passenger flow in all passenger flows.

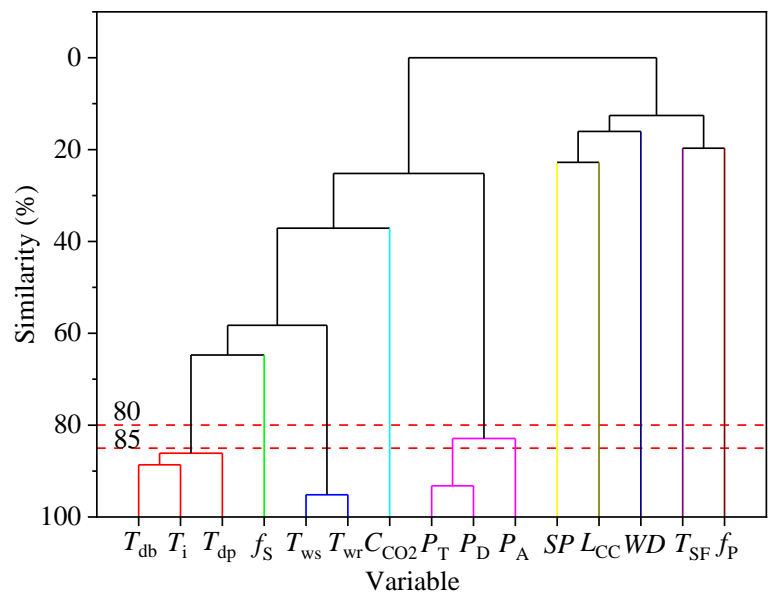

(a) Operation parameters

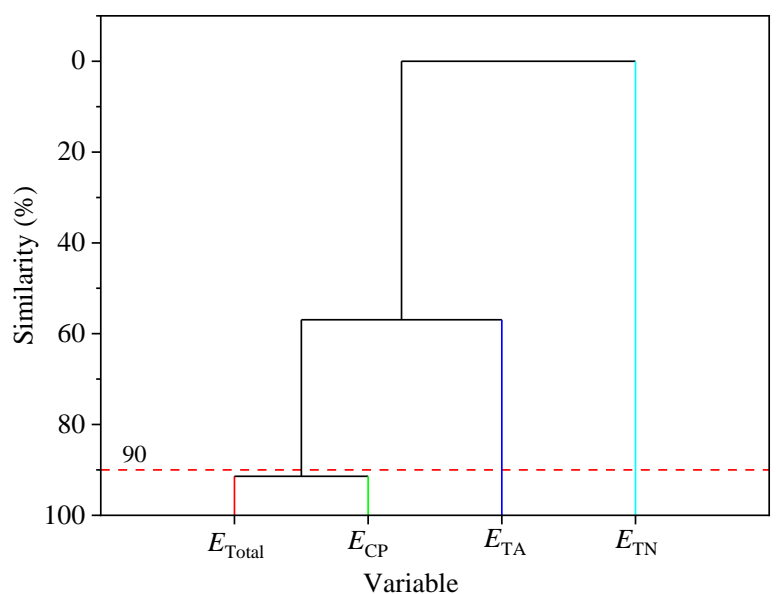

(b) Energy classification

Fig. 10. The dendrograms of cluster analysis

\subsection{Correlation analysis}

The relevance of the above parameters to the total energy consumption $\left(E_{\text {Total }}\right)$ and its three components of $E_{\mathrm{CP}}, E_{\mathrm{TA}}$ and $E_{\mathrm{TN}}$ are studied in this section. Kolmogorov-Smirnov test showed none of these data followed normal distribution. Spearman correlation analysis to the hourly data in 2017 gave the simple correlation coefficients between any two factors as shown in Figure 11. Those that showed a strong correlation with the total energy consumption were outdoor dry bulb temperature, total passenger flow, departure passenger flow, arrival passenger flow, supplying fan frequency, return water temperature, supply water temperature. The factors that showed a strong correlation with the $E_{\mathrm{CP}}$ and the $E_{\mathrm{TA}}$ were similar, both including outdoor dry bulb temperature, indoor temperature, supplying fan frequency, supply water temperature, return water temperature. But there was one more factor of dew temperature for the $E_{\mathrm{CP}}$. Total 
1 passenger flow, arrival passenger flow and departure passenger flow showed strong correlation 2 with the $E_{\mathrm{TN}}$. Low cloud cover, $\mathrm{CO}_{2}$ concentration and supply air temperature had low correlation with all energy consumption categories whereas surface pressure and supply fan

4 5 frequency showed medium correlation with them.

$\square T_{\mathrm{db}} \square T_{\mathrm{dp}} \square S P \square L_{\mathrm{CC}} \square W D$
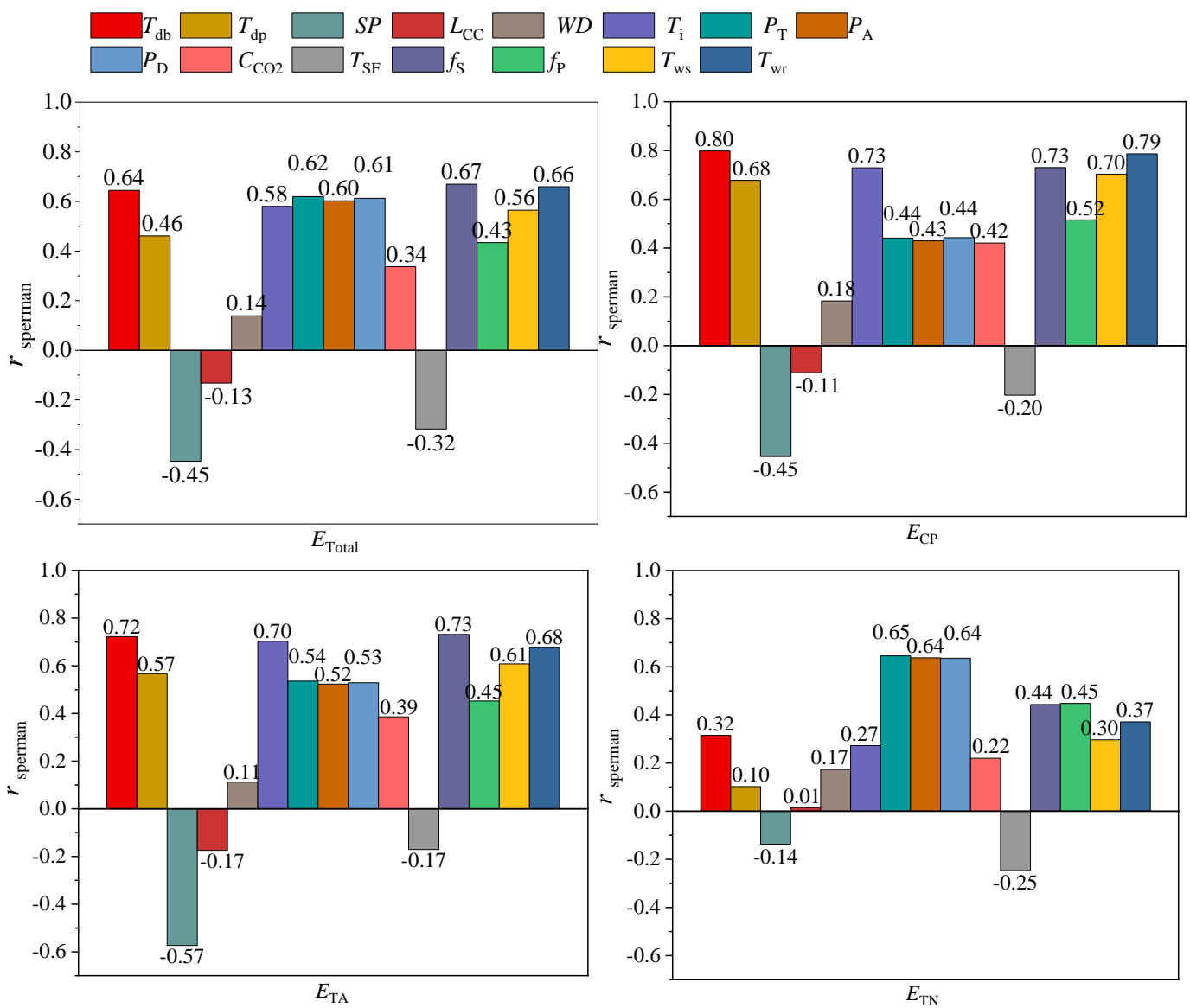

Fig. 11. Energy consumption correlation coefficient in 2017

Removing the influence of other parameters, the partial correlation coefficient of passenger flow, meteorological data, supply fan frequency and water system parameters to $E_{\mathrm{Total}}, E_{\mathrm{CP}}, E_{\mathrm{TA}}$ and $E_{\mathrm{TN}}$ are shown in Figure 12, where the main variables were chosen from Figure 10 (a) adopting a criterion of $85 \%$ similarity.

Total passenger flow, departure passenger flow, outdoor dry bulb temperature and arrival passenger flow had the strongest correlation with the $E_{\text {Total }}$ in the listed sequence. Outdoor dry bulb temperature and outdoor dew point temperature had strong correlation with the $E_{\mathrm{CP}}$. The variables that had strong correlation with the $E_{\mathrm{TA}}$ include total passenger flow, departure passenger flow, outdoor dry bulb temperature, arrival passenger flow and supply fan frequency. 
1 And total passenger flow, departure passenger flow, arrival passenger flow showed strong correlation with $E_{\mathrm{TN}}$. The partial correlation coefficients were not in agreement with simple correlation coefficients in that the partial correlation coefficients between the $E_{\mathrm{Tota}}, E_{\mathrm{CP}}, E_{\mathrm{TA}}$ and the variables were smaller while that between $E_{\mathrm{TN}}$ and the passenger flows were stronger. The partial correlation coefficients can reflect the reality in a better way than the simple correlation coefficients. The key factors that influence the $E_{\text {Total }}$ are the passenger flow and outdoor meteorological data. For the $E_{\mathrm{CP}}$, the key factor is outdoor meteorological data. The $E_{\mathrm{TA}}$ is mainly affected passenger flow, meteorological data and supply fan frequency whereas $E_{\mathrm{TN}}$ is significantly affected by passenger flow only.

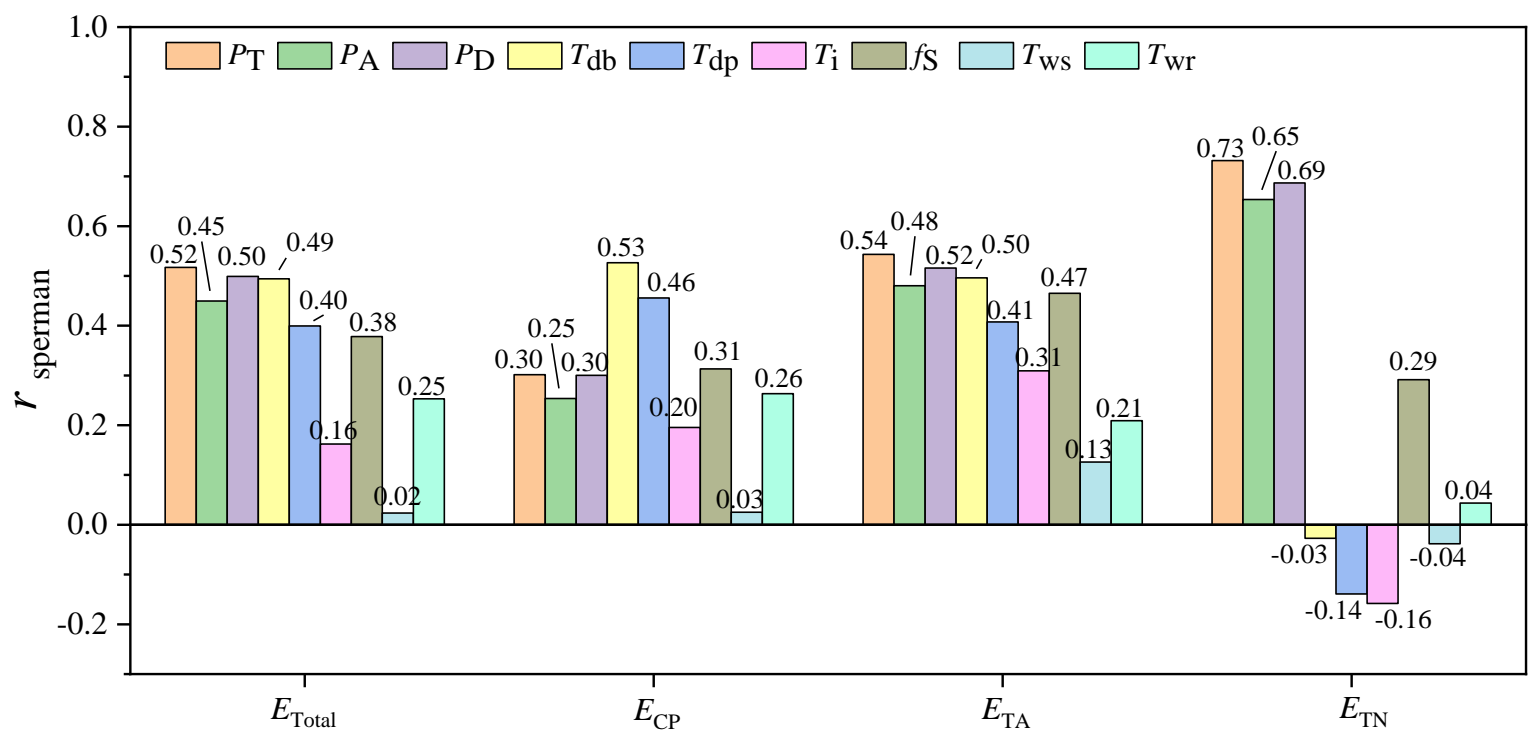

Fig. 12. Energy consumption partial correlation coefficient in 2017

Repeating the partial correlation analysis using the daily data and monthly data for temperatures, supply fan frequency and passenger flow from 2016 and 2019 gave the result shown in Figure 13 (a, b). Comparing against Figure 12 showed that with daily data, the correlation between the passenger flow and all categories of energy consumptions became weaker, but the outdoor meteorological data showed stronger correlation. It was interesting that the correlation coefficients for monthly data were between hourly data and daily data. Actually, monthly data and hourly data gave similar correlation coefficients between the energy consumptions and their affecting factors, whereas daily data gave generally a weaker correlation. However, it was worth noting that if daily or monthly data were to be used, the sample shall include more than one year. Otherwise, the analysis could lead to wrong conclusions as shown in Figure 13 (c, d) where the daily $E_{\text {Total }}$ and monthly $E_{\mathrm{TN}}$ showed negative correlation with the arrival passenger flow, which obviously violated the common perception. This happened because energy 
1 consumptions changed on a yearly basis whereas passenger flow increased from year to another

2 (Figure 4 (b)). It required at least 2 years sample to reflect the characteristics of both data sets.

3

5

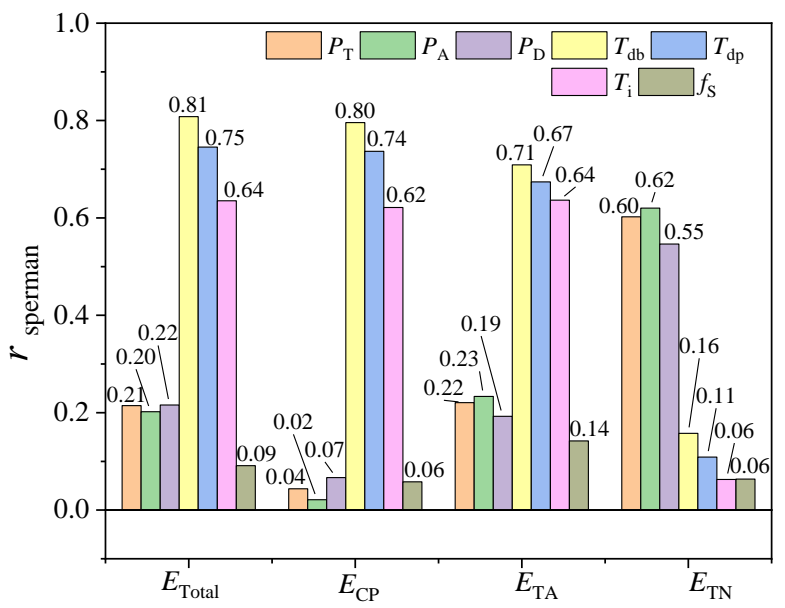

(a) Daily data in 2016-2019

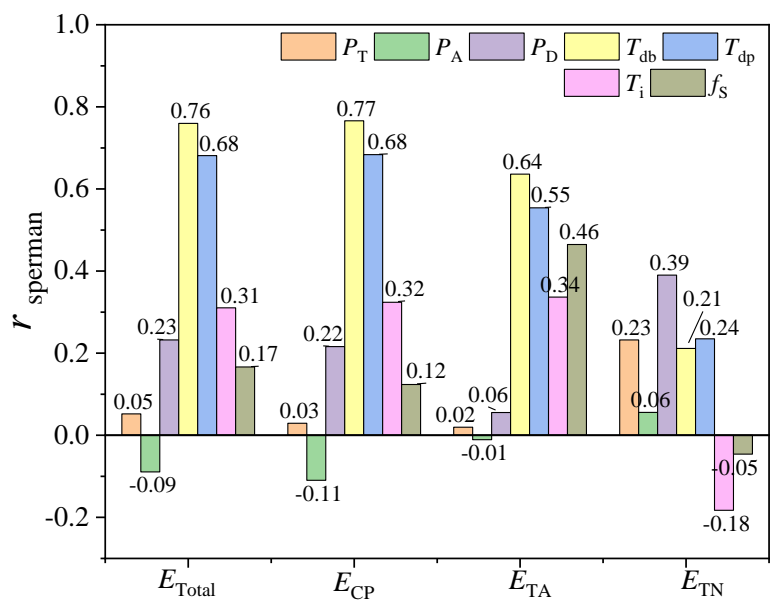

(c) Daily data in 2017

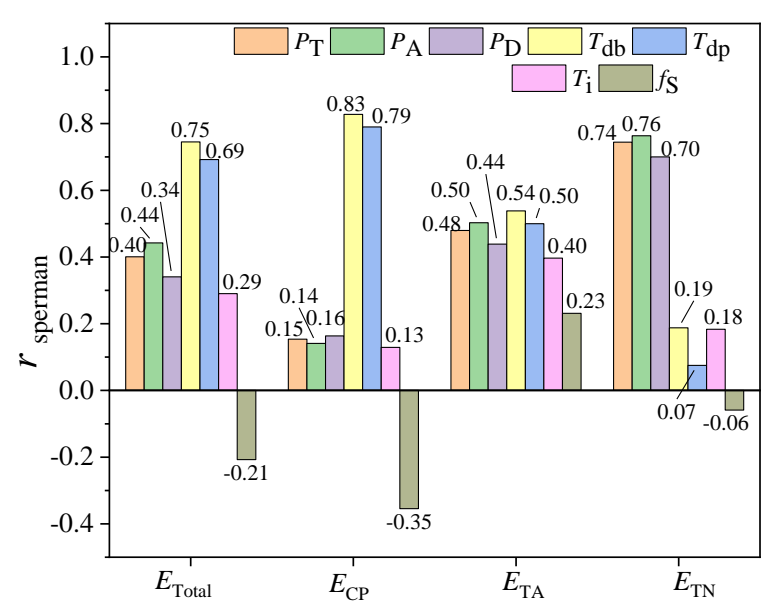

(b) Monthly data in 2016-2019

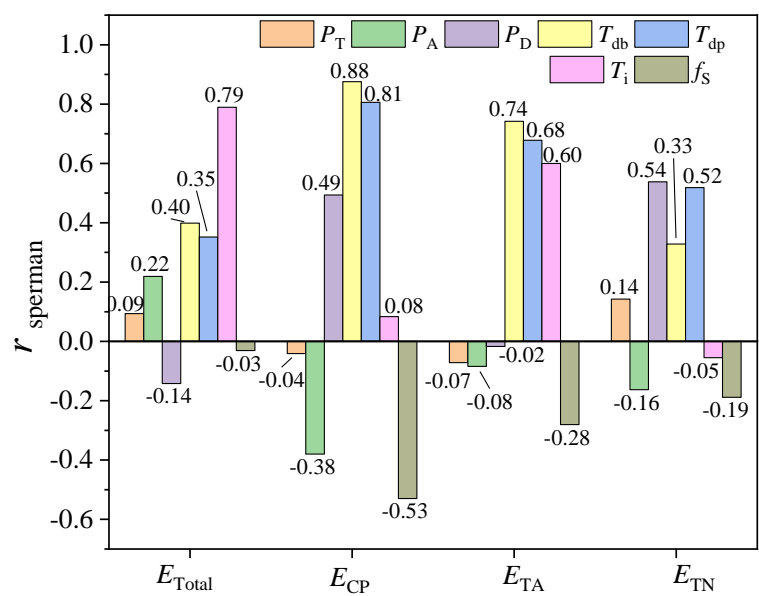

(d) Monthly data in 2017

Fig. 13. Energy consumption partial correlation coefficient in 2016-2019

\subsection{Regression analysis}

An initial energy consumption prediction was obtained by regression analysis to the monthly data. According to Figure 12 and 13 and the clustering analysis result, the main variables for the $E_{\text {Total }}$ are meteorological data represented by outdoor dry bulb temperature $\left(T_{d b}\right)$ and passenger flow, represented by the total passenger flow $\left(P_{T}\right)$. The regression equation gives:

$$
E_{\text {Total }}=26.41369 T_{d b}+9.06328 \times 10^{-4} P_{\mathrm{T}}
$$


The $\mathrm{P}=0.0(<0.05)$ of the F-test of the regression equation indicates that the regression equation is significant. Variable $T_{d b}$ regression coefficient t test $\mathrm{P}=8.7 \times 10^{-13}$, variable $P_{\mathrm{T}}$ regression coefficient $t$ test $\mathrm{P}=1.6 \times 10^{-21}$, both are less than 0.05 , indicating a significant linear relationship between the dependent variable and the independent variable. The coefficient of determination $\left(\mathrm{R}^{2}\right)$ of the fitting curve is 0.99571 , and adjusted coefficient of determination (adjusted $\mathrm{R}^{2}$ ) is $0.99553(>0.8)$, which indicates that the fitting curve is excellent. The fitting curve is shown in Figure 14 (a).

The only variable for the $E_{\mathrm{CP}}$ is meteorological data represented by outdoor dry bulb temperature $\left(T_{d b}\right)$ and the regression equation gives:

$$
E_{\mathrm{CP}}=-738.67567+172.20928 T_{d b}-14.03224 T_{d b}{ }^{2}+0.38966 T_{d b}{ }^{3}
$$

The coefficient of determination $\left(\mathrm{R}^{2}\right)$ of the fitting curve is 0.96888 , and adjusted coefficient of determination (adjusted $\mathrm{R}^{2}$ ) is $0.96676(>0.8)$, which indicates that the fitting curve is excellent. The fitting curve is shown in Figure 14 (b).

The monthly data of the supply fan frequency showed some distortions and was removed from the fitting analysis. Thus, only the meteorological data represented by outdoor dry bulb temperature $\left(T_{d b}\right)$ and passenger flow, represented by the total passenger flow $\left(P_{\mathrm{T}}\right)$ are included in the regression analysis for $E_{\mathrm{TA}}$ and the regression equation is:

$$
E_{\mathrm{TA}}=18.19165 T_{d b}+5.50023 \times 10^{-6} P_{\mathrm{T}}
$$

The F-test of the regression equation gives $\mathrm{P}=0.0$, which is smaller than 0.05 , indicating that the regression equation is significant. For Variable $T_{d b}$ and $P_{\mathrm{T}}$, the regression coefficient $\mathrm{t}$ test gives $\mathrm{P}=7.5 \times 10^{-16}(<0.05)$ and $\mathrm{P}=0.853(>0.05)$ respectively indicating a significant linear relationship between the $E_{\mathrm{TA}}$ and the $T_{d b}$ and a not significant linear relationship between the $E_{\mathrm{TA}}$ and the $P_{\mathrm{T}}$. The coefficient of determination $\left(\mathrm{R}^{2}\right)$ of the fitting curve is 0.980 , and adjusted coefficient of determination (adjusted $\mathrm{R}^{2}$ ) is $0.979(>0.8)$, meaning the fitting is satisfactory. The fitting curve is shown in Figure 14 (c).

$E_{\mathrm{TN}}$ is only related to passenger flows, therefore, the variables chosen are the departure 
1 passenger flow $\left(P_{D}\right)$ and the arrival passenger flow $\left(P_{A}\right)$, which gives the regression equation 2 as

$$
E_{\mathrm{TN}}=0.00184 P_{D}+2.20641 \times 10^{-4} P_{A}
$$

5

Again, quality check for the regression analysis gives $\mathrm{P}=0.0$ for the F-test of the regression equation. The t test of the regression coefficient for Variable $P_{D}$ and $P_{\mathrm{A}}$ gives $\mathrm{P}=6.0 \times 10^{-4}(<0.05)$ $\mathrm{P}=0.679$ ( $>0.05)$ respectively, indicating a significant linear relationship between the $E_{\mathrm{TN}}$ and the $P_{D}$ and a not significant linear relationship between the $E_{\mathrm{TN}}$ and the $P_{\mathrm{A}}$. The coefficient of determination $\left(\mathrm{R}^{2}\right)$ of the fitting curve is 0.994 , and adjusted coefficient of determination (adjusted $R^{2}$ ) is $0.993(>0.8)$. The fitting curve is shown in Figure $14(d)$.

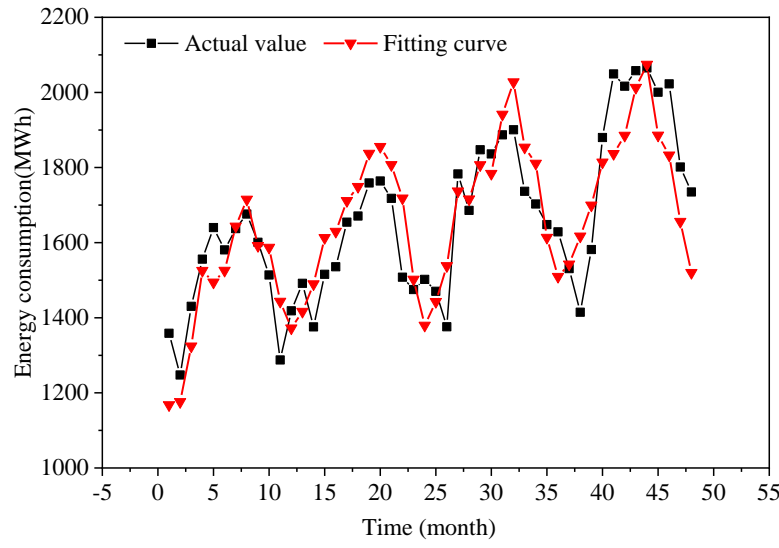

(a) Total energy $\left(E_{\text {Total }}\right)$

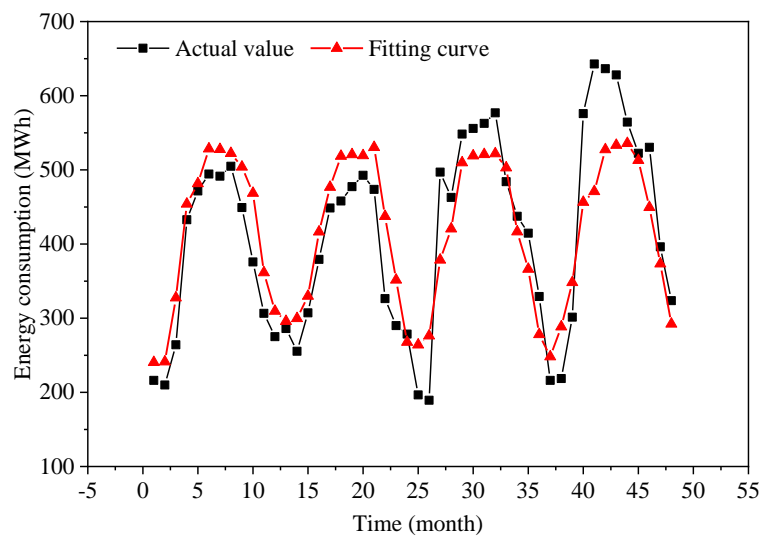

(c) Terminal HVAC system $\left(E_{\mathrm{TA}}\right)$

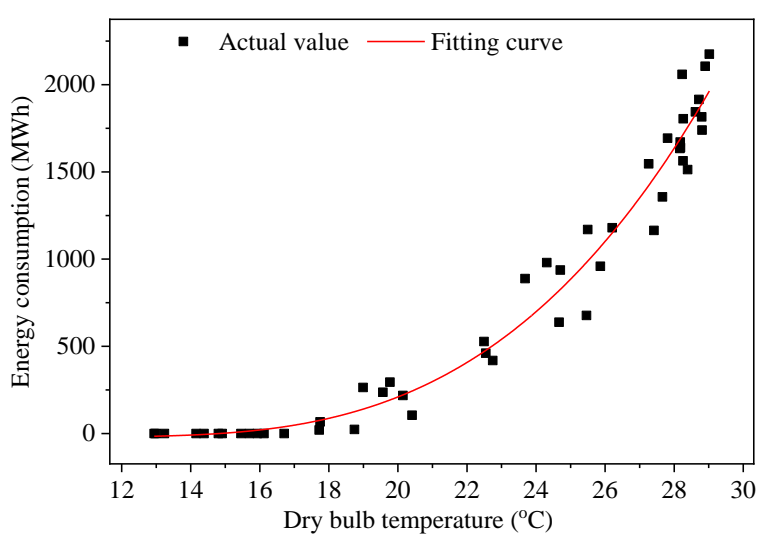

(b) Cooling plant $\left(E_{\mathrm{CP}}\right)$

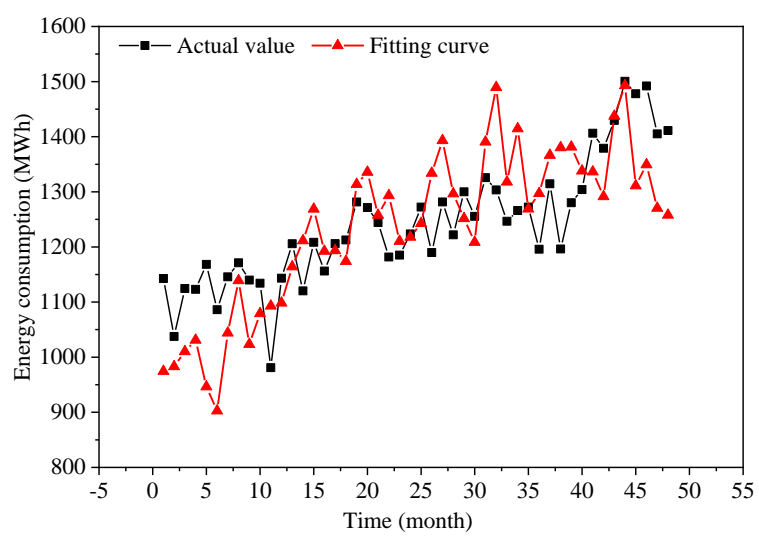

(d) Terminal exclude HVAC system $\left(E_{\mathrm{TN}}\right)$

Fig. 14. Regression prediction curve of energy consumption

Analysis to the total passenger flow and various energy consumption data from 2016 to 2019 showed they were all subject to exponential relationship and can be described by the following 
10

equation:

$$
Y=Y_{0}+A e^{-x / t}
$$

Fitting against the recorded data gives the parameters for $E_{\mathrm{Total}}, E_{\mathrm{CP}}, E_{\mathrm{TA}}$ and $E_{\mathrm{TN}}$ as shown in Table 2. The adjust $\mathrm{R}^{2}$ for these four fittings are $0.9902,0.9988,0.8188,0.8977$, all above 0.8 , indicating a good fitting. The result is shown in Figure 15.

Table 2 Fitting model parameters

\begin{tabular}{llllll}
\hline Parameters & $Y_{0}$ & $\mathrm{~A}$ & $\mathrm{t}$ & $\mathrm{R}^{2}$ & adjust $^{2}$ \\
\hline$E_{\mathrm{Total}}$ & 27142.847 & $1.62254 \times 10^{-4}$ & -897469.417 & 0.99673 & 0.9902 \\
$E_{\mathrm{CP}}$ & 9178.123 & $3.45892 \times 10^{-12}$ & 460784.413 & 0.99961 & 0.99883 \\
$E_{\mathrm{TA}}$ & 4396.637 & $4.68293 \times 10^{-4}$ & -1060013.843 & 0.93961 & 0.81884 \\
$E_{\mathrm{TN}}$ & 13327.354 & 0.04343 & -1399103.770 & 0.96589 & 0.89767 \\
\hline
\end{tabular}

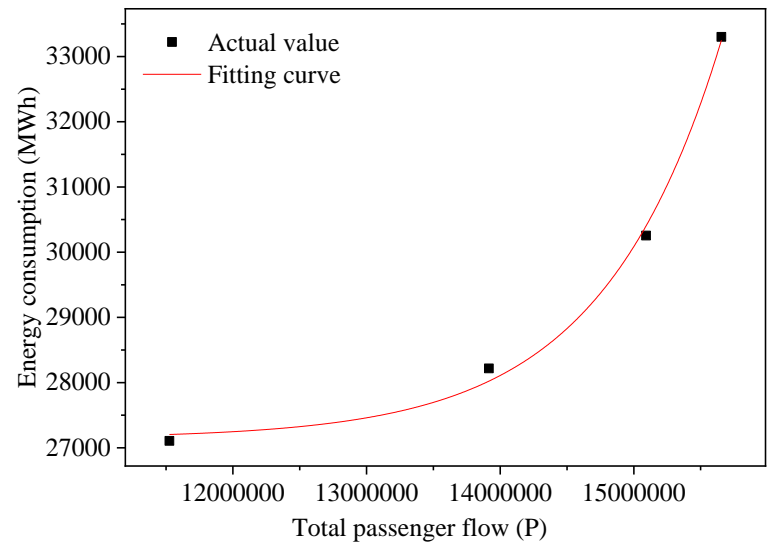

(a) Total energy $\left(E_{\text {Total }}\right)$

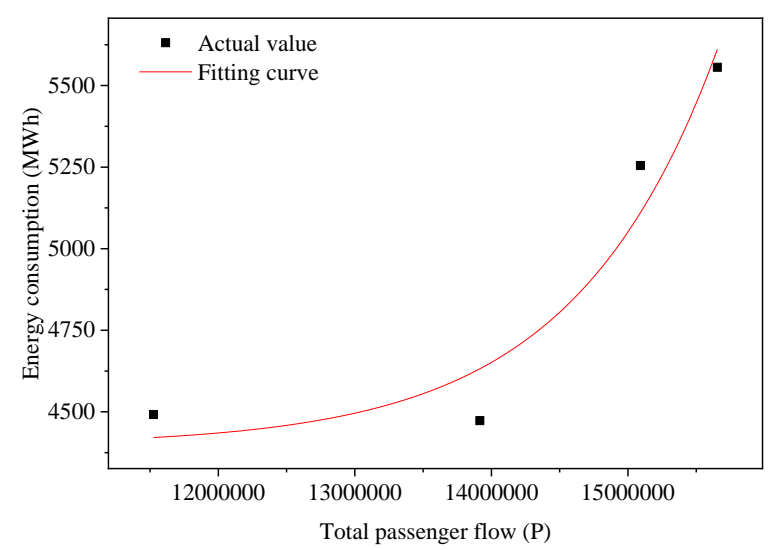

(c) Terminal HVAC system $\left(E_{\mathrm{TA}}\right)$

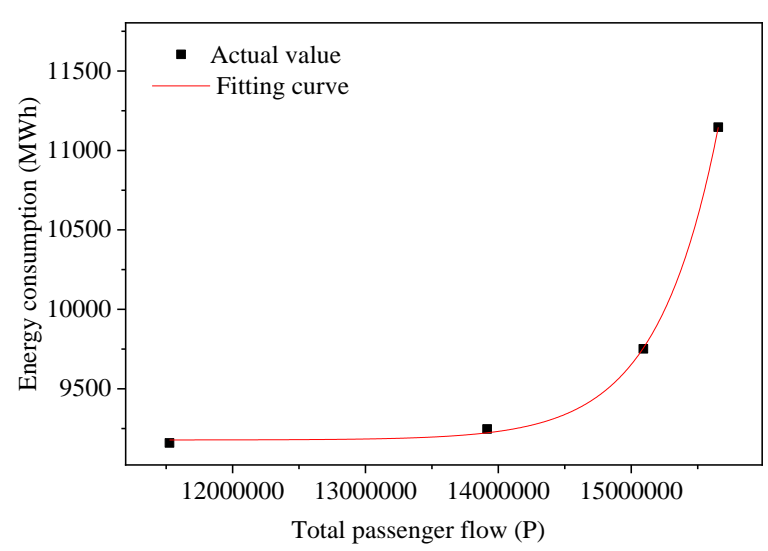

(b) Cooling plant $\left(E_{\mathrm{CP}}\right)$

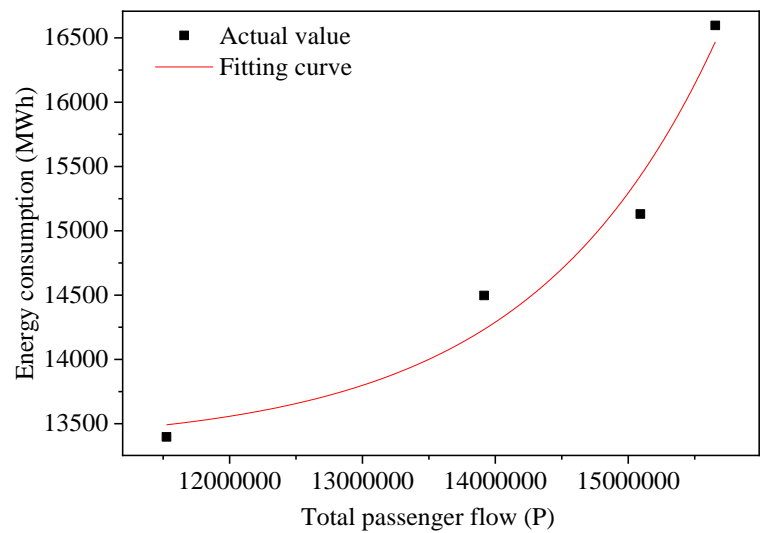

(d) Terminal exclude HVAC system $\left(E_{\mathrm{TN}}\right)$

Fig. 15. Fitting curve of energy consumption and passenger flow 
1 Through the above analysis, it can be seen that the energy consumption shows strong correlation with outdoor meteorological parameters and passenger flow. However, the hourly and daily energy consumption distribution does not follow any simple proportional relationship with these parameters and cannot be described by simple mathematical formulas. Their relationship can be analyzed and predicted by higher-level data mining methods, such as simulation [3739][37], artificial neural network algorithms [40-42].

\section{Conclusions}

This paper presented a study to the energy consumption of airports based on the operating data of an airport in south China during 2016-2019. The climate is characterized by hot summer and warm winter, so HVAC system is only provided for summer and the HVAC system energy consumption accounts for $48.6-50.4 \%$ of the total energy consumption of the terminal. The energy consumptions were divided into four categories for the convenience and this paper studied the spatial and temporal distribution characteristics of various energy consumptions. Main conclusions from the study include:

1) From 2016-2019, the total energy, outdoor temperature, indoor temperature and indoor $\mathrm{CO}_{2}$ concentration changed in a yearly period, but the passenger flow increased monthly. The total energy consumption and the HVAC system energy consumption showed uneven distribution in temporal and special dimension. The energy consumption by all other systems, though also showed non-uniform space distribution, was constant within one year and can be described by its daily average value.

2) Clustering analysis shows outdoor dry bulb temperature, indoor temperature and outdoor dew temperature can be combined as the one parameter and represented by dry bulb temperature. The supply water temperature and return water temperature can be combined as one parameter. The total passenger flow, departure passenger flow and the arrival passenger flow can be put in one category with $80 \%$ similarity. All other parameters, such as low cloud cover, surface pressure, wind direction, supply air temperature, supply fan frequency, extract fan frequency, and $\mathrm{CO}_{2}$ concentration can be treated as independent parameter. Clustering analysis to energy consumptions show very high similarity between the total energy consumption and the cooling plant energy consumption. 
3) It was showed that the key factors that influence the total energy consumption are the passenger flow and outdoor meteorological data by partial correlation analysis to the various energy consumptions. For the cooling plant energy consumption, the key factor is outdoor meteorological data. The Terminal HVAC system energy consumption is mainly affected passenger flow, meteorological data and supply fan frequency whereas the energy consumption by all other terminal systems is significantly affected by passenger flow only.

4) Equations were established for the prediction of the total energy consumption and the energy consumption by the terminal HVAC system and all other terminal systems respectively based on regression analysis to monthly data. The total passenger flow and various energy consumption data from 2016 to 2019 follow the exponential distribution and can be described by $\mathrm{Y}=\mathrm{Y} 0+\mathrm{Ae}^{-\mathrm{x} / \mathrm{t}}$.

This is probably the first comprehensive studies to airport energy consumptions based on multiple year recording data in China. It is believed that the data reported can work as benchmark for energy simulations, and the conclusions, together with future studies, will provide strong feedback to improve airport designs and operations.

\section{Acknowledgement}

The research described in this paper was supported by the National Key R\&D Program of China (No. 2018YFC0705000). Special thanks to all the airport staffs who provided kind help.

\section{References}

[1] Civil Aviation Administration of China, National development and reform commission, ministry of transport of the People's republic of China, The 13th Five-Year Plan for the Development of Civil Aviation in China, http://www.caac.gov.cn/XXGK/XXGK/FZGH/201704/t20170405_43505.html; 2016 [accessed 20 March 2020] (in Chinese).

[2] Kotopouleas A, Nikolopoulou M. Evaluation of comfort conditions in airport terminal buildings. Building and Environment. 2017; 130:162-178. 
https://doi.org/10.1016/j.buildenv.2017.12.031.

[3] Civil Aviation Administration of China. Civil Aviation Energy Conservation and Emission Reduction "Thirteenth Five-Year Plan". Civil Airport Terminal Green Performance Research and Test Report. http://www.caac.gov.cn/XXGK/XXGK/GFXWJ/201711/t20171106_47447.html; 2017 [accessed 20 March 2020] (in Chinese).

[4] China Building Energy Conservation Association. "China Building Energy Research Report (2016)”. http://www.efchina.org/Reports-zh/report-20170710-1-zh; 2017 [accessed 20 March 2020] (in Chinese).

[5] Zeren F. Energy performance analysis of Adnan Menderes International Airport. Master's Thesis, Science in Energy Engineering, Izmir Institute of Technology, Izmir, Turkey, March 2010.

[6] Yang L, Li K, Yang G, Zhang X C. The design of airport flood lighting energy-saving control system. Applied Mechanics \& Materials. 2014; 492:499-502. https://doi.org/10.4028/www.scientific.net/AMM.492.499.

[7] Ortega Alba S, Manana M. Energy Research in Airports: A Review, Energies. 2016; 9 (5):1-19. https://doi.org/10.3390/en9050349.

[8] Dai M H, Zhou Z P, Xue X. Test and energy consumption analysis of air-conditioning systems in terminal building of Guilin Liangjiang International Airport. Applied Mechanics \& Materials. 2012; 170-173:2652-2656. https://doi.org/10.4028/www.scientific.net/AMM.170-173.2652.

[9] Vakiloroaya V, Samali B, Fakhar A, Pishghadam K. A review of different strategies for HVAC energy saving. Energy Conversion and Management. 2014; 77:738-754. https://doi.org/10.1016/j.enconman.2013.10.023.

[10] Balaras C A, Dascalaki E, Gaglia A, Droutsa K. Energy conservation potential, HVAC installations and operational issues in Hellenic airports. Energy and Buildings. 2003; 35:1105-1120. https://doi.org/10.1016/j.enbuild.2003.09.006.

[11] Pichatwatana K, Wang F, Roaf S, Anunnathapong M. An integrative approach for indoor environment quality assessment of large glazed air-conditioned airport terminal in the $\begin{array}{llll}\text { tropics. } & \text { Energy }\end{array}$ https://doi.org/10.1016/j.enbuild.2017.05.007.

[12] Ekici B B, Aksoy U T. Prediction of building energy consumption by using artificial neural networks. Advances in Engineering Software. 2009; 40(5):356-362. https://doi.org/10.1016/j.advengsoft.2008.05.003. 
[13] Chen J, Xie K. A prediction model based on unbiased grey Markov for airport energy consumption prediction. 2013 Chinese Automation Congress, Changsha. 2013; 291-294, https://doi.org/10.1109/CAC.2013.6775745.

[14] Huang H, Chen L, Hu E. A new model predictive control scheme for energy and cost savings in commercial buildings: An airport terminal building case study. 2015; 89:203216. https://doi.org/10.1016/j.buildenv.2015.01.037.

[15] Balaras C A, Dascalaki E, Gaglia A, Droutsa K. Energy conservation potential, HVAC installations and operational issues in Hellenic airports. Energy and Buildings. 2003; 35 (11):1105-1120. https://doi.org/10.1016/j.enbuild.2003.09.006.

[16] Yang C, Jin X, Du Z, Fan B, Yang X. Modeling and simulation of the airport terminal air conditioning system based on Energy plus. Journal of Shanghai Jiaotong University. 2010; 44:745-748+754 (in Chinese).

[17] Fang X, Jin X, Fan B, Du Z, Zeng X. Evaluation on air conditioning's operating property of airport terminal based on hierarchal cluster. CIESC Journal. 2012; 63(S2):89-94 (in Chinese).

[18] Mao N, Song MJ, Pan DM, Deng SM. Comparative studies on using RSM and TOPSIS methods to optimize residential air conditioning systems. Energy. 2018; 144: 98-109. https://doi.org/10.1016/j.energy.2017.11.160.

[19] Mao N, Song MJ, Deng SM. Application of TOPSIS method in evaluating the effects of supply vane angle of a task/ambient air conditioning system on energy utilization and thermal comfort. Applied Energy. 2016; 180: 536-545. https://doi.org/10.1016/j.apenergy.2016.08.011.

[20] CIBSE Guide A: Environmental Design. The Chartered Institution of Building Services Engineers, London, 2015.

[21] ASHRAE Handbook of Fundamentals. American Society of Heating, Refrigerating and Air Conditioning Engineers Inc. New York. USA. 2017.

[22] Tatsuhiro Yamamoto, Akihito Ozaki, Myongyang Lee, Hideki Kusumoto. Fundamental study of coupling methods between energy simulation and CFD. Energy and Buildings. 2018; 159:587-599. https://doi.org/10.1016/j.enbuild.2017.11.059.

[23] Tatsuhiro Yamamoto, Akihito Ozaki, Myonghyang Lee. Development of a Thermal Environment Analysis Method for a Dwelling Containing a Colonnade Space through Coupled Energy Simulation and Computational Fluid Dynamics. Energies. 2019; 12(13): 2560. https://doi.org/10.3390/en12132560. 
1 [24] Liu XC, Liu XH, Zhang T, Li L. An investigation of the cooling performance of airconditioning systems in seven Chinese hub airport terminals. Indoor and Built Environment. December 2019. https://doi.org/10.1177/1420326X19891645.

[25] Liu XC, Li L, Liu XH, Zhang T. Analysis of passenger flow and its influences on HVAC systems: An agent-based simulation in a Chinese hub airport terminal. Building and Environment. 2019; 154:55-67. https://doi.org/10.1016/j.buildenv.2019.03.011.

[26] Liu XC, Li L, Liu XH, Zhang T, Rong XY, Yang L. Field investigation on characteristics of passenger flow in a Chinese hub airport terminal. Building and Environment. 2018; 133:51-61. https://doi.org/10.1016/j.buildenv.2018.02.009.

[27] Mambo A D, Efthekhari M, Thomas S. Fuzzy supervisory control strategies to minimize energy use of airport terminal buildings. 18th International Conference on Automation and Computing (ICAC). IEEE. 2012; p.1-6.

[28] Issued by the Ministry of housing and urban rural development. Code for design of heating, ventilation and air conditioning of civil buildings: GB 50736-2012. China Construction Industry Press, 2012 (in Chinese).

[29] Liu JL, Liu L, Ma XY, Fu Q, Wang HJ, Zhang ZH, et al. Study on the spatial variability of soil salinity in different soil layers at different scales. Journal of Applied Basic Science and Engineering. 2018; 2:305-312 (in Chinese).

[30] Jahangir M H, Khatibi A. Site selection of harmonic pressure water energy convertor systems on the south coast of the Caspian Sea using cluster analysis. Sustainable Energy Technologies and Assessments. 2020; 38. https://doi.org/10.1016/j.seta.2020.100678.

[31] Deborah J Rumsey. Statistics for dummies (2nd Edition). Hoboken, NJ. Wiley Publishing. 2011, p.284.

[32] Rudolf J Freund, William J Wilson, Ping Sa. Regression analysis: statistical modeling of a response variable. Translated by Shen Chonglin. Chongqing University Press, Chongqing; 2012.

[33] Li Sulan. Data Analysis and R Software. Second Edition. Science Press, Beijing; 2017 (in Chinese).

[34] Ye Weiping. Origin 9.1Technology drawing and data analysis. China Machine Press, Beijing; 2017 (in Chinese).

[35] Guidelines for energy efficiency evaluation on civil airport terminals (MH/T 5112-2016). http://www.caac.gov.cn/XXGK/XXGK/BZGF/HYBZ/201708/t20170804_45792.html; 2016 [accessed 18 May 2020] (in Chinese). 

http://www.caac.gov.cn/XXGK/XXGK/TZTG/201701/t20170113_41720.html; 2017 [accessed 18 May 2020] (in Chinese).

[37] Fonseca i Casas P, Casanovas J, Ferran X. Passenger flow simulation in a hub airport: An application to the Barcelona International Airport. Simulation modelling practice and theory. 2014; 44:78-94. http://dx.doi.org/10.1016/j.simpat.2014.03.008.

[38] Xing ZW, He C, Luo Q, Jiang XF, Liu C, Cong W. Terminal building short-term passenger flow forecast based on two-tier K-nearest neighbor algorithm. Journal of Beijing University of Aeronautics and Astronautics. 2019; 45 (1): 26-34 (in Chinese).

[39] Wu PY, Pitchforth J, Mengersen K. A hybrid queue-based Bayesian network framework for passenger facilitation modelling. Transportation Research Part $\mathrm{C}$ Emerging Technologies. 2014; 46:247-260. http://dx.doi.org/10.1016/j.trc.2014.05.005.

[40] Nasruddin, Sholahudin, Satrio P, Mahlia T M I, Giannetti N, Saito K. Optimization of HVAC system energy consumption in a building using artificial neural network and multiobjective genetic algorithm. Sustainable Energy Technologies and Assessments. 2019; 35:48-57. https://doi.org/10.1016/j.seta.2019.06.002.

[41] Ghritlahre H K, Chandrakar P, Ahmad A. Application of ANN model to predict the performance of solar air heater using relevant input parameters. Sustainable Energy Technologies and Assessments. 2020; 40. https://doi.org/10.1016/j.seta.2020.100764.

[42] Wang J, Wang Y, Li Z, Li H, Yang H. A combined framework based on data preprocessing, neural networks and multi-tracker optimizer for wind speed prediction. Sustainable Energy Technologies and Assessments. 2020; 40. https://doi.org/10.1016/j.seta.2020.100757. 